\title{
Ensilados químicos y biológicos. Una alternativa de aprovechamiento integral y sustentable de los residuos pesqueros en la Argentina
}

\author{
Adriana Fernández Herrero* \\ Instituto Nacional de Investigación y Desarrollo Pesquero (INIDEP), Paseo Victoria Ocampo No 1, Escollera Norte, \\ B7602HSA - Mar del Plata, Argentina
}

Marine and

Fishery Sciences

MAFIS Journal of the Instituto Nacional de (INIDEP)

This work is licensed under a Creative Commons AttributionNonCommercial-ShareAlike 4.0 International License
RESUMEN. Durante el procesamiento y comercialización de los productos pesqueros se producen residuos orgánicos que se destinan principalmente a la elaboración de harina y aceite de pescado. En zonas donde no existen plantas de harina de pescado, los residuos provenientes de la pesca y la acuicultura terminan volcados en forma directa sobre fuentes hídricas o a orillas de éstas causando problemas de contaminación. Para evitar el impacto que puedan causar, y revalorizar los residuos pesqueros, existen alternativas viables desde el punto de vista económico y ambiental, como es la producción de ensilado para la obtención de un producto de buena calidad nutricional y microbiológicamente estable. El ensilado se utiliza cada vez más como ingrediente para piensos en la cría de animales y en la acuicultura, así también como fertilizante. El objetivo de esta revisión fue presentar los métodos de producción de ensilados, su composición nutricional y su utilización como insumo alimenticio o fertilizante en los campos de la acuicultura y agronomía.

Palabras clave: Ensilado de pescado, subproductos pesqueros, descartes pesqueros, aprovechamiento de recursos, aplicaciones potenciales.

\section{Chemical and biological ensilates. An alternative for the integral and sustainable use of fishing waste in Argentina}

ABSTRACT. During the processing and marketing of fishery products, organic waste is produced which are mainly used for the production of fishmeal and fish oil. In areas where there are no fishmeal plants, residues from fishing and aquaculture end up dumped directly onto water sources or on their banks, causing pollution problems. In order to avoid the impact that they may cause, and to revalue fishing waste, there are viable alternatives from an economic and environmental point of view, such as the production of silage to obtain a product of good nutritional quality and microbiologically stable. Silage is increasingly used as a feed ingredient in animal husbandry and aquaculture, as well as a fertilizer. The objective of this review was to present silage production methods, their nutritional composition and their use as feed or fertilizer in the fields of aquaculture and agronomy.

Key words: Fish silage, fishery by-products, fishery discards, resource development, potential applications. 


\section{INTRODUCCIÓN}

\section{Generalidades}

\section{Recursos pesqueros y acuicolas en el mundo}

Los recursos pesqueros y acuícolas de los ecosistemas tanto marinos como de agua dulce constituyen una de las mayores fuentes de proteína animal del mundo. Según la Organización de las Naciones Unidas para la Alimentación y la Agricultura (FAO 2020), la producción mundial de pescado (incluyendo crustáceos y moluscos) alcanzó unas 179.000.000 t en 2018, de las cuales 82.000 .000 t procedieron de la acuicultura. Del total general, alrededor del $88 \%$ se destinó al consumo humano y el $12 \%$ restante se destinó a usos no alimentarios: el $82 \%$ de esta cantidad se utilizó para producir harina y aceite de pescado, mientras que el resto se comercializó para producir peces ornamentales y organismos de cultivo (por ejemplo, semillas, alevines o adultos pequeños para cría), como cebo, en usos farmacéuticos, para alimento de animales de compañía o como materia prima para la alimentación directa en la acuicultura y para la cría de ganado y animales de peletería.

En la Argentina, la producción pesquera marina alcanzó en 2019 las 781.327 t, de las cuales $314.326 \mathrm{t}$ correspondieron a la especie de mayor importancia económica de la Argentina, Merluccius hubbsi (Argentina 2020a; Tabla 1). Las pesquerías continentales tienen una importancia significativa debido al volumen exportable y al impacto social que ejerce en cuanto a su aporte a la seguridad alimentaria y a las economías familiares regionales. Más del $90 \%$ de la producción pesquera continental del país proviene de las pesquerías de la cuenca del Río de la Plata, que registró volúmenes totales de extracción para 2019 de 25.485 t. De éstas, las capturas de sábalo (Prochilodus lineatus) aportan la mayor proporción (Argentina 2020b).
Tabla 1. Producción por sector pesquero en la Argentina durante 2019

Table 1. Production by fishing sector in Argentina during 2019

Actividad

Volumen (t)

Pesca captura

781.327

Pesca continental

25.485

Acuicultura

La Argentina es uno de los pocos países de Latinoamérica que presenta una acuicultura escasamente desarrollada. Esta actividad se inició en la década de los setenta con el cultivo de trucha arco iris (Oncorhynchus mykiss) en la región patagónica andina. En la misma década, en la Provincia del Chubut se realizaron los primeros ensayos en mar, con el mejillón (Mytilus platensis), vieira (Zygochlamys patagonica) y ostra plana (Crassostrea gigas) (Zárate 2013). El lento crecimiento de la actividad se produjo de forma escalonada hasta una producción máxima en 2014 que apenas superó las 4.000 t, valor que se redujo gradualmente en años posteriores (Tablas 1 y 2) hasta aproximadamente 2.592 t en 2019 (Panné Huidobro 2019).

Los avances científicos de los últimos 50 años han permitido mejorar en gran medida los conocimientos acerca del funcionamiento de los ecosistemas acuáticos así como la conciencia mundial sobre la necesidad de gestionarlos de forma sostenible. Veinticinco años después de la aprobación del Código de Conducta para la Pesca Responsable (FAO 1995), en la actualidad se reconoce ampliamente la importancia de utilizar los recursos pesqueros y acuícolas de forma responsable y se prioriza este objetivo. Desde 2015 , estos esfuerzos fueron prioridad con miras a abordar en particular, de forma coherente $y$ coordinada, el Objetivo de Desarrollo Sostenible (ODS) $\mathrm{N}^{\mathrm{o}} 14$ "Conservar y utilizar en forma sostenible los océanos, los mares y los recursos 
Tabla 2. Producción acuícola argentina durante 2019.

Table 2. Argentine aquaculture production during 2019.

\begin{tabular}{lr}
\hline Especie & Volumen (t) \\
\hline Pacu (Piaractus mesopotamicus) & $1.063,05$ \\
Trucha (Oncorhyncus mykiss) & $1.201,74$ \\
Carpas (Cyprinus carpio, Hypopthalmichtys molitrix, & 103,81 \\
$\quad$ Aristichtys nobilis, Ctenopharyngodon idella) & \\
Salmon de río (Brycon orbignyanus) & 55,00 \\
Surubí (Pseudoplatystoma fasciatum y P. coruscans) & 87,11 \\
Tilapia (Oreochromis niloticus) & 23,70 \\
Dorado (Salminus brasiliensis) & 12,39 \\
Sábalo (Prochilodus lineatus) & 7,66 \\
Ostra (Crassostrea gigas) & 15,50 \\
Mejillones (Mytilus edulis, M. chilensis y Aulacomya ater) & 4,00 \\
Boga (Leoporinus obtusidens) & 9,63 \\
\hline Total & $2.592,19$ \\
\hline
\end{tabular}

marinos para el desarrollo sostenible", y otros ODS pertinentes para la pesca y la acuicultura. A tal fin, se acepta que la aplicación de políticas de ordenación de la pesca y la acuicultura con base científica, junto con regímenes previsibles y transparentes para la utilización y el comercio de pescado a nivel internacional, constituyen criterios sustantivos mínimos para la sostenibilidad de la pesca y la acuicultura (FAO 2020).

\section{Revalorización de subproductos pesqueros}

En la industria de los productos pesqueros existen tanto residuos de pescado, como también especies de bajo valor comercial que son descartadas. Según las estimaciones de FAO (2020), alrededor de 70 millones de toneladas de pescados y mariscos se procesan al año mediante eviscerado, fileteado, congelación, enlatado o curado. Durante el procesamiento y comercialización se producen subproductos (35-50\%) compuestos en general por cabezas $(9-12 \%)$, vísceras $(12-18 \%)$, piel $(1-3 \%)$, espinas $(9-15 \%)$ y escamas $(5 \%)$.

Los subproductos pesqueros contienen una gran cantidad de proteínas, lípidos, vitaminas, pigmentos y minerales (Kristinsson y Rasco 2000; Gbogouri et al. 2004). Estos subproductos se pueden utilizar mediante distintos procesos industriales en la elaboración de ensilados e hidrolizados proteínicos que tienen ciertas aplicaciones en la obtención de productos dietéticos (quitosano), productos farmacéuticos (aceites), pigmentos naturales (tras la extracción) y cosméticos (colágeno), en las industrias del pienso para animales de compañía y para peces, en la producción de biodiesel y biogás, entre otras aplicaciones (FAO 2020). Los generados a escala industrial se destinan principalmente a la elaboración de harina y aceite de pescado, para lo cual se requiere la instalación de plantas harineras exigentes en energía y ávidas de cantidades importantes de materia prima.

Los residuos provenientes de la pesca en zonas donde no existen plantas de harina de pescado (HP), junto con los de la pesca artesanal y acuícola, son dispuestos directamente en fuentes hídricas o a orillas de éstas o reciben el mismo trata- 
miento que los residuos sólidos urbanos, situación que puede causar problemas de contaminación.

Actualmente, los esfuerzos encaminados a la posibilidad de dar un uso adecuado a los residuos generados de la pesca y acuicultura y, evitar el impacto que puedan causar, han llevado a buscar opciones de revalorización de los mismos que sean viables desde el punto de vista ambiental y económico. Una alternativa viable a la HP es destinar los residuos de la pesca a la producción de ensilados por ser un proceso de fácil elaboración y que no exige alta inversión, obteniéndose un producto de buena calidad nutricional y microbiológicamente estable (Bello 1994; Berenz 1994; Toledo y Llanes Iglesias 2006).

El objetivo de esta revisión fue presentar los métodos de producción de ensilado de pescado (EP), sus características nutricionales, así como su utilización como insumo alimenticio o fertilizante en los campos de la acuicultura y agronomía.

\section{Ensilado de pescado}

\section{Historia del ensilado}

El ensilado de subproductos de pescado constituye una técnica antigua de preservación de la materia orgánica. La producción de ensilado se remonta a los años 1920, cuando Virtanen utilizó ácidos sulfúrico y clorhídrico para el mantenimiento del forraje vegetal. Este método se adoptó en Suecia por Edin en la década de los treinta, evaluándose la acidificación y la fermentación anaeróbica como métodos para la preservación de subproductos de pescado. Esta técnica continuó desarrollándose en Dinamarca en años posteriores, donde dichos subproductos se destinaban principalmente a la formulación de dietas para engorde de animales de granja, como aves y cerdos (Bote1lo 2005). Desde la década del cuarenta, el ensilado ha sido producido en varios países, como Polonia, Dinamarca, países escandinavos y los Países Bajos, los cuales siguieron el procesamiento del ensilado en escala comercial (Ramírez 2013).
En los años ochenta, la FAO impulsó las investigaciones sobre ensilados biológicos en el ámbito latinoamericano. Los resultados se expusieron en la Segunda Consulta de expertos sobre Tecnología de Productos Pesqueros en América Latina celebrada en Montevideo en 1989 (FAO 1990). Entre 2001-2002, en el Centro de Desarrollo Acuícola de Aguas Cálidas (CENADAC) conjuntamente con el Instituto Nacional de Investigación y Desarrollo Pesquero (INIDEP), ambos de la Argentina, se implementó la tecnología de ensilado químico como una alternativa para la disminución de costos para las dietas de peces. Posteriormente, en 2004 reaparece el tema pero con el desarrollo de ensilados biológicos (Manca y Carrizo 2002; Panné Huidobro et al. 2006).

\section{Definición de ensilado}

En la industria de los productos pesqueros existen tanto residuos de pescado como también especies descartadas que poseen un alto contenido proteico. Ambas tienen la particularidad de sufrir rápidos procesos de alteración, produciendo malos olores, problemas de polución y contaminación ambiental. Una de las alternativas para aprovechar estos "residuos" la constituyen los ensilados, que son un producto semilíquido pastoso, elaborado a partir de pescado entero o de residuos del mismo en medio ácido (Seibel y Souza Soares 2003; Borghesi 2004; Ferraz de Arruda 2004; Toledo y Llanes Iglesias 2006). El descenso del $\mathrm{pH}$ puede obtenerse por la acción de ácidos (ensilado químico) o por fermentación microbiana (ensilado biológico) que utiliza una fuente de carbohidratos para producir el ácido in situ (Ramírez Ramírez 2009) en donde se activan las enzimas autolíticas (principalmente proteolíticas) que modifican las características intrínsecas del pescado e inhiben el desarrollo de bacterias deteriorantes y patógenas, confiriéndole al producto una conservación prolongada en el tiempo (Copes et al. 2006). Normalmente, se realiza a temperatura ambiente y el almacenamiento de este sistema durante cierto tiempo conducirá a los 
cambios bioquímicos deseados. Este producto se puede emplear cuando el $\mathrm{pH}$ se estabiliza a valores cercanos a 4 y se mantiene con una composición semejante a la materia prima por alrededor de 30 días (Ferraz de Arruda 2004; Borghesi et al. 2008). Varios autores demostraron que el éxito en la producción de ensilado está relacionado con ciertas precauciones en la preparación del material residual, que debe molerse previamente y mezclarse bien para evitar la acumulación de material sin tratamiento. Idealmente, el material destinado a la producción de EP debe triturarse en partículas de 3,0 a 4,0 mm de diámetro. El ácido (agregado o producido) actúa para permitir la preservación de la biomasa pastosa, y la agitación de la mezcla, además de proporcionar la uniformidad deseada, evita que las partes no tratadas se pudran por la acción las bacterias deteriorantes (Maia y de Oliveira Sales 2013).

La escala de producción es adaptable a los volúmenes de captura y puede ser aplicado tanto a la pesca industrial como artesanal y a la acuicultura. El producto final es fácil de manejar, ya que solo necesita contenedores sellados que pueden variar en tamaño según los requisitos de transporte final, desde bidones de 501 hasta tanques o silos de 30 t (Ramírez 2013).

\section{Tipos de ensilado de pescado}

\section{Ensilado químico}

Los ensilados químicos (EQ) se basan en la utilización de ácidos orgánicos (fórmico, propiónico, acético, cítrico) o inorgánicos (sulfúrico, clorhídrico, fosfórico), éstos generan un ambiente que inhibe el desarrollo de los microorganismos putrefactivos y patógenos (Berenz 1997). Distintos autores han trabajado en determinar que ácidos y en que proporciones son más eficientes para la preparación de ensilados con distintas especies de peces (Ferraz de Arruda 2004).

El descenso de $\mathrm{pH}$ de los ensilados depende de la materia prima y de la proporción y tipo de ácido (Tabla 3). Es importante señalar que los áci- dos ejercen dos efectos sobre los microorganismos, aunque estrechamente relacionados. En primer lugar, existe un efecto antimicrobiano debido a la acidez del medio. En segundo lugar, la forma disociada del ácido permite su difusión libre a través de la membrana celular hacia el citoplasma suprimiendo sistemas enzimáticos y de transporte de nutrientes (Pölönen 2000; Roth 2000 ).

En los primeros EQ se trabajó con ácidos minerales como sulfúrico y clorhídrico, y/o mezclas de ellos, con muy buenos resultados. En trabajos más recientes se prefiere la utilización de ácidos orgánicos. Éstos, son generalmente más caros que los minerales pero producen ensilados menos ácidos y no exigen una neutralización antes del uso. Si solo se usan ácidos minerales, el $\mathrm{pH}$ debe estar alrededor de 2 para detener el crecimiento microbiano y esto requiere aumentar el $\mathrm{pH}$ agregando una base antes de incluirlo en el alimento (Olsen y Toppe 2017).

Los ácidos más comúnmente utilizados eran: sulfúrico, fórmico, acético y propiónico. El ácido fórmico es uno de los ácidos orgánicos más elegidos como acidificante en dietas de animales. Fernández Herrero et al. (2008, 2009, 2019a, 2019b) utilizaron el ácido fórmico en distintas proporciones $(2,5$ al 4,5\%) con residuos de peces marinos, obteniendo buenos resultados. En varios estudios se recomienda una mezcla de ácidos fórmico y propiónico (Anbe 2011; De et al. 2020). La mezcla de ácido sulfúrico con ácido fórmico o ácido fosfórico en distintas proporciones demostró ser eficiente en la producción de EQ. Esta posibilidad de sustituir el ácido fórmico por ácido fosfórico es interesante, ya que permite la reducción de los costos de producción de ensilado (Góngora y Ruiz 2008; Botello et al. 2010; Llanes Iglesias et al. 2012; Viglezzi 2012; Yupanqui Pajuelo 2013; Vásquez Zuluaga 2015; Tezel et al. 2016; Fernández Herrero et al. 2017a, 2018). En otros trabajos se buscó reducir costos usando ácido acético (Crexi et al. 2009; Reyes Ramos 2010; Perea Román et al. 2017; Lopes de Lima et al. 2020) y ácido clorhídrico (Tanuja et al. 2017). 
Tabla 3. Tecnologías empleadas en la preparación de los ensilados químicos de pescado.

Table 3. Technologies used in the preparation of chemical fish silage.

\begin{tabular}{|c|c|c|c|}
\hline Materia prima & Ácidos & País & Bibliografía \\
\hline Merluccius hubbsi & Ácido sulfúrico:ácido fórmico & Argentina & Góngora y Ruiz (2008) \\
\hline Merluccius hubbsi & (2,5-3,5 y 4,5\%) ácido fórmico & Argentina & Fernández Herrero et al. (2008) \\
\hline Cyprinus carpio & $10 \%$ ácido acético glacial & Brasil & Crexi et al. (2009) \\
\hline Salilota australis & 4,5\% ácido fórmico & Argentina & Fernández Herrero et al. (2009) \\
\hline Opisthonema oglinum & $\begin{array}{l}\text { Ácido sulfúrico-fórmico / } \\
\text { ácido fosfórico-cítrico }\end{array}$ & Cuba & Botello et al. (2010) \\
\hline Hypostomus plecostomus & $\begin{array}{l}\text { Ácido fosfórico-cítrico / } \\
\text { ácido sulfúrico-acético }\end{array}$ & México & Reyes Ramos (2010) \\
\hline Sardinella brasiliensis & Ácido fórmico / propiónico & Brasil & Anbe (2011) \\
\hline Oreochromis niloticus & $\begin{array}{l}2 \% \text { ácido sulfúrico y } \\
1 \% \text { ácido fórmico }\end{array}$ & Cuba & Llanes Iglesias et al. (2012) \\
\hline Cyprinus carpio & $\begin{array}{l}\text { Ácido fórmico / ácido } \\
\text { sulfúrico }\end{array}$ & Argentina & Viglezzi (2012) \\
\hline Trachurus murphy & $\begin{array}{l}\text { Ácido fórmico / ácido } \\
\text { sulfúrico } 3 \%\end{array}$ & Perú & Yupanqui Pajuelo (2013) \\
\hline Epinephelus malabaricus & (2-2,5 y 3\%) ácido fórmico & India & Ramasubburayan et al. (2013) \\
\hline Piaractus brachypomus & $\begin{array}{l}\text { Ácido fórmico y el ácido } \\
\text { sulfúrico }\end{array}$ & Colombia & Vásquez Zuluaga (2015) \\
\hline Desecho pesquero & $\begin{array}{l}1,5 \% \text { ácido formico - } 1,5 \% \\
\text { sulfúrico }\end{array}$ & Turquía & Tezel et al. (2016) \\
\hline Cyprinus carpio & $\begin{array}{l}1,5 \% \text { ácido fórmico - 1,5\% } \\
\text { ácido clorhídrico }\end{array}$ & India & Tanuja et al. 2017) \\
\hline Acanthistius patachonicus & $\begin{array}{l}\text { 3,0-3,5\% ácido } \\
\text { fórmico-fosfórico o fórmico }\end{array}$ & Argentina & Fernández Herrero et al. (2017a) \\
\hline Oncorhynchus mykiss & Ácido fórmico / ácido acético & Colombia & Perea Román et al. (2017) \\
\hline Residuos de pescado & $\begin{array}{l}\text { (2,5-3,5 y } 4.5 \%) \text { ácido } \\
\text { sulfúrico o fórmico }\end{array}$ & India & Palkar et al. (2017) \\
\hline Merluccius hubbsi & $\begin{array}{l}3,0 \% \text { ácido fórmico-fosfórico / } \\
3,0 \% \text { fórmico }\end{array}$ & Argentina & Fernández Herrero et al. (2018) \\
\hline Merluccius hubbsi & $3,0 \%$ ácido fórmico & Argentina & $\begin{array}{l}\text { Fernández Herrero et al. (2019a, } \\
\text { 2019b) }\end{array}$ \\
\hline Residuos de pescado & $\begin{array}{l}\text { Ácido fórmico / } \\
\text { ácido propiónico }\end{array}$ & India & De et al. (2020) \\
\hline $\begin{array}{l}\text { Pseudoplatystoma corruscans / } \\
\text { Piaractus brachypomus }\end{array}$ & $10 \%$ ácido acético & Brasil & Lopes de Lima et al. (2020) \\
\hline
\end{tabular}

Actualmente, en Escandinavia, Polonia, Dinamarca y los Países Bajos se pueden encontrar mercados bien establecidos para el EQ a partir de subproductos de pescado. Se utiliza ensilado de 
pescado blanco, como alternativa a la HP y se vende a un precio más bajo en una base de peso seco equivalente (Ramírez 2013). En Noruega existen alrededor de 50 plantas de procesamiento de salmón, la mayoría de las cuales llevan a cabo la conservación ácida de subproductos. También se utiliza para preservar los subproductos del procesamiento de peces silvestres cuando la producción tradicional de HP no es conveniente. Algunos buques pesqueros más grandes utilizan la preservación ácida (ensilado ácido) de subproductos y captura secundaria (Olsen et al. 2014).

\section{Ensilado biológico}

Para la obtención del ensilado biológico (EB) se requiere una fuente de carbohidratos y microorganismos que permitan la fermentación láctica y la consecuente disminución del pH (Llanes Iglesias et al. 2007a). Bacterias ácido lácticas (Lactobacillus spp., Bacillus spp., etc), hongos (Aspergillus spp.) y levaduras (Saccharomyces spp.) se encuentran entre los microorganismos que utilizan las materias orgánicas como los carbohidratos (almidones: como harina de maíz, trigo, arroz, yuca, papa, cebada; azúcares: melaza, miel, sacarosa, glucosa) como fuente de energía para el crecimiento y carbono para la síntesis de la biomasa celular durante la fermentación. Los ácidos orgánicos producidos a través de la fermentación dan como resultado la reducción de la acidez del producto y previenen el crecimiento de otros microorganismos deteriorantes, proporcionando un medio adecuado para la actividad de las enzimas proteolíticas del propio pescado (presentes principalmente en las vísceras) que degradarán las proteínas a péptidos y aminoácidos libres (Areche et al. 1992; Bello 1994). Este proceso de producción de ensilado es más complicado que la acidificación directa, ya que debe existir un cultivo iniciador, pero podría ser adecuado en países donde los azúcares fermentables están fácilmente disponibles (Olsen y Toppe 2017).

Las bacterias ácido lácticas producen ácido láctico durante el proceso y se sabe que algunas cepas de Aspergillus y Sacchoromyces producen ácido cítrico a partir de carbohidratos (Khodanazary et al. 2013). Complementado la actividad de las bacterias ácido lácticas en los ensilados, se suele utilizar en la elaboración de los mismos ácido sórbico. Su uso hace que se prevenga la formación de hongos, mohos o levaduras.

El EB presenta una serie de ventajas: sencilla manipulación, posibilidad de agregar diferentes cepas de bacterias ácido lácticas, permite la utilización de carbohidratos de costo razonable y de fácil disponibilidad en la zona, la no destrucción de aminoácidos esenciales que hace que la proteína retenga su valor nutritivo y la obtención de un producto de sabor y olor atractivo, agradable y apetecible (Panné Huidobro et al. 2006).

Varios autores trabajaron en la utilización de subproductos pesqueros con distintas combinaciones de bacterias ácido lácticas y fuentes de carbohidratos para producir EB, obteniendo productos con alto valor nutricional (Tabla 4). Utilizaron diferentes bacterias ácido lácticas como Lactobacillus plantarum (Vázquez et al. 2010; Góngora et al. 2012; Khodanazary et al. 2013; Vásquez Zuluaga 2015; Ortega Toro y Hoyos Concha 2016; Sánchez Trujillo et al. 2016; Fernández Herrero et al. 2017b, 2017c, 2019a; Harrabi et al. 2017; Perea Román et al. 2017); Lactobacillus spp. (Cipriano Salazar et al. 2015); bacterias del yogur, Lactobacilus casei, Lactobacilus acidofilus, Lactobacillus bulgaricus y Streptococcus thermophilus (Sesto 2010; Spanopoulos et al. 2010; Fernández Herrero et al. 2011, 2013, 2015a, 2015b, 2015c, 2016; Llanes Iglesias et al. 2012; Gama Ortiz 2013); Pedioccoccus acidilactici y Enterococcus faecium (Rai et al. 2010) entre otros. En todos los casos, se añade una fuente fermentable de hidratos de carbono como melaza (Spanopoulos et al. 2010; Baldovino Pacce et al. 2011; Guedes 2012; Gama Ortiz 2013; Góngora 2013; Cipriano Salazar et al. 2015; Vásquez Zuluaga 2015; Churacutipa Mamani 2016; Sánchez Trujillo et al. 2016; Jato- 
Tabla 4. Tecnologías empleadas en la preparación de los ensilados biológicos de pescado. Table 4. Technologies used in the preparation of biological fish silage.

\begin{tabular}{|c|c|c|c|c|}
\hline Materia prima & Microorganismos & Fuente de carbono & País & Bibliografía \\
\hline Cyprinus carpio & $\begin{array}{l}\text { Lactobacillus bulgaricus / } \\
\text { Streptococcus thermophilus }\end{array}$ & Miel / sacarosa & Argentina & Sesto (2010) \\
\hline $\begin{array}{r}\text { Procesamiento } \\
\text { de mejillones }\end{array}$ & $\begin{array}{l}\text { Lactobacillus plantarum / } \\
\text { Lactobacillus casei }\end{array}$ & Glucosa & España & Vázquez et al. (2010) \\
\hline $\begin{array}{l}\text { Thunnus albacares / } \\
\text { Oreochromis }\end{array}$ & Lactobacillus casei & Melaza & México & Spanopoulos et al. (2010) \\
\hline $\begin{array}{l}\text { Labeo rohita / } \\
\text { Catla catla }\end{array}$ & $\begin{array}{l}\text { Enterococcus faecium / } \\
\text { Pedioccoccus acidilactic }\end{array}$ & Dextrosa & India & Rai et al. (2010) \\
\hline Residuo de pescado & Yogurt & Harina de yuca & Colombia & Perea Román et al. (2011) \\
\hline Cyprinus carpio & $\begin{array}{l}\text { Lactobacillus bulgaricus / } \\
\text { Streptococcus thermophilus }\end{array}$ & Miel & Argentina & $\begin{array}{l}\text { Fernández Herrero et al. } \\
\text { (2011) }\end{array}$ \\
\hline $\begin{array}{l}\text { Cynoscion guatucupa } \\
\text { у Merluccius hubbsi }\end{array}$ & $\begin{array}{l}\text { Lactobacillus delbruecki / } \\
\text { Streptococcus thermophilus }\end{array}$ & Melaza /sacarosa & Uruguay & $\begin{array}{l}\text { Baldovino Pacce et al. } \\
\text { (2011) }\end{array}$ \\
\hline Tilapia & Lactobacillus acidophilus & Miel & Cuba & $\begin{array}{l}\text { Llanes Iglesias et al. } \\
\text { (2012) }\end{array}$ \\
\hline Merluccius hubbsi & $\begin{array}{l}\text { Lactobacillus plantarum / } \\
\text { Lactobacillus buchneri }\end{array}$ & Glucosa /sacarosa & Argentina & Góngora et al. (2012) \\
\hline Pseudoplatystoma spp. & $\begin{array}{l}\text { Lactobacillus sakei / } \\
\text { Weissela viridensis }\end{array}$ & Maicena / melaza & Brasil & Guedes (2012) \\
\hline Merluccius hubbsi & $\begin{array}{l}\text { Lactobacillus lactis / } \\
\text { Lactobacillus fermentum / } \\
\text { Lactobacillus sakei }\end{array}$ & Melaza & Argentina & Góngora (2013) \\
\hline $\begin{array}{l}\text { Dosidiscus gigas y } \\
\text { Argopecten } \\
\text { ventricusus }\end{array}$ & $\begin{array}{l}\text { Lactobacillus casei y } \\
\text { Streptococcus thermophilus }\end{array}$ & Melaza & México & Gama Ortiz (2013) \\
\hline Engraulis anchoita & $\begin{array}{l}\text { Lactobacillus bulgaricus / } \\
\text { Streptococcus thermophilus }\end{array}$ & Miel & Argentina & $\begin{array}{l}\text { Fernández Herrero et al. } \\
\text { (2013) }\end{array}$ \\
\hline $\begin{array}{l}\text { Clupeonella } \\
\text { engrauliformis }\end{array}$ & $\begin{array}{l}\text { Lactobacillus plantarum / } \\
\text { Bacillus subtilis }\end{array}$ & Harina de trigo & Irán & Khodanazary et al. (2013) \\
\hline Engraulis anchoita & $\begin{array}{l}\text { Lactobacillus bulgaricus / } \\
\text { Streptococcus thermophilus }\end{array}$ & Hez de cebada & Argentina & $\begin{array}{l}\text { Fernández Herrero et al. } \\
\text { (2015a) }\end{array}$ \\
\hline Plecostomus spp. & Lactobacillus spp. & Melaza & México & $\begin{array}{l}\text { Cipriano Salazar et al. } \\
\text { (2015) }\end{array}$ \\
\hline Merluccius hubbsi & $\begin{array}{l}\text { Lactobacillus bulgaricus / } \\
\text { Streptococcus thermophilus }\end{array}$ & Sacarosa & Argentina & $\begin{array}{l}\text { Fernández Herrero et al. } \\
(2015 b)\end{array}$ \\
\hline Piaractus brachypomus & Lactobacillus plantarum & Melaza / suero & Colombia & Vásquez Zuluaga (2015) \\
\hline Micropogonias furnieri & $\begin{array}{l}\text { Lactobacillus bulgaricus / } \\
\text { Streptococcus thermophilus }\end{array}$ & Sacarosa & Argentina & $\begin{array}{l}\text { Fernández Herrero et al. } \\
(2015 \mathrm{c})\end{array}$ \\
\hline
\end{tabular}


Tabla 4. Continuación.

Table 4. Continued.

\begin{tabular}{|c|c|c|c|c|}
\hline Materia prima & Microorganismos & Fuente de carbono & País & Bibliografía \\
\hline Oncorhynchus mykiss & Lactobacillus plantarum & Melaza & Colombia & $\begin{array}{l}\text { Sánchez Trujillo et al. } \\
\text { (2016) }\end{array}$ \\
\hline Merluccius hubbsi & $\begin{array}{l}\text { Lactobacillus bulgaricus / } \\
\text { Streptococcus thermophilus }\end{array}$ & Sacarosa & Argentina & $\begin{array}{l}\text { Fernández Herrero et al. } \\
\text { (2016) }\end{array}$ \\
\hline Tilapia roja & Lactobacillus plantarum & Harina de yuca & Colombia & $\begin{array}{l}\text { Ortega Toro y Hoyos } \\
\text { (2016) }\end{array}$ \\
\hline Oncorhynchus mykis & Aspergillus orizae & Melaza & Perú & $\begin{array}{l}\text { Churacutipa Mamani } \\
\text { (2016) }\end{array}$ \\
\hline Micropogonias furnieri & Lactobacillus plantarum & Sacarosa & Argentina & $\begin{array}{l}\text { Fernández Herrero et al. } \\
(2017 b)\end{array}$ \\
\hline Merluccius hubbsi & Lactobacillus plantarum & Sacarosa & Argentina & $\begin{array}{l}\text { Fernández Herrero et al. } \\
(2017 \mathrm{c})\end{array}$ \\
\hline $\begin{array}{l}\text { Penaeus kerathurus y } \\
\text { Octopus vulgaris }\end{array}$ & Lactobacillus plantarum & Sacarosa & Túnez & Harrabi et al. (2017) \\
\hline Dicentrarchus labrax & $\begin{array}{l}\text { Lactobacillus brevis / } \\
\text { Enterococcus gallinarum }\end{array}$ & Melaza & Turquía & Özyurt et al. (2017) \\
\hline Oncorhynchus mykis & Lactobacillus plantarum & Melaza / yuca & Colombia & Perea Román et al (2017) \\
\hline Arapaima gigas & Bacterias lácticas & Melaza / plátano & Perú & Sosa Espinosa (2017) \\
\hline $\begin{array}{l}\text { Pseudupeneus } \\
\text { maculatus }\end{array}$ & Yogurt & Melaza / maicena & Brasil & $\begin{array}{l}\text { Jatobá y Oliveira Filho } \\
\text { (2017) }\end{array}$ \\
\hline $\begin{array}{l}\text { Residuos de pescado } \\
\text { marino }\end{array}$ & Lactobacillus spp. & Sacarosa / mango & México & $\begin{array}{l}\text { Ramírez Ramirez et al. ' } \\
\text { (2018) }\end{array}$ \\
\hline $\begin{array}{l}\text { Acanthistius } \\
\text { patachonicus }\end{array}$ & Lactobacillus plantarum & Sacarosa & Argentina & $\begin{array}{l}\text { Fernández Herrero et al. } \\
\text { (2019a) }\end{array}$ \\
\hline Cabezas de langostino & Lactobacillus fermentus & Melaza & Perú & Castillo et al. (2019) \\
\hline $\begin{array}{l}\text { Pseudoplatystoma } \\
\text { corruscans / Piaractus } \\
\text { brachypomus }\end{array}$ & Yogurt & Sacarosa & Brasil & $\begin{array}{l}\text { Lopes de Lima et al. } \\
\text { (2020) }\end{array}$ \\
\hline
\end{tabular}

bá y Oliveira Filho 2017; Özyurt et al. 2017; Perea Román et al. 2017; Sosa Espinosa 2017; Castillo et al. 2019), dextrosa (Rai et al. 2010), glucosa (Vázquez et al. 2010; Góngora et al. 2012), sacarosa (Sesto 2010; Baldovino Pacce et al. 2011; Góngora et al. 2012; Fernández Herrero et al. 2015b, 2015c, 2016, 2017b, 2017c, 2019a; Harrabi et al. 2017; Ramírez Ramírez et al. 2018; Lopes de Lima et al. 2020), miel (Sesto 2010;
Fernández Herrero et al. 2011, 2013; Llanes Iglesias et al. 2012), maicena (Guedes 2012; Jatobá y Oliveira Filho 2017), harina de trigo (Khodanazary et al. 2013), hez de malta de cebada (Fernández Herrero et al. 2015a), yuca / suero lácteo / plátano / mango (Perea Román et al. 2011, 2017; Vásquez Zuluaga 2015; Ortega Toro y Hoyos 2016; Sosa Espinosa 2017; Ramírez Ramírez et al. 2018). 


\section{Composición nutricional del ensilado de pesca- do}

El pescado y los productos pesqueros contienen agua, proteínas y otros compuestos de nitrógeno, lípidos, carbohidratos, minerales y vitaminas. La composición bioquímica varia de una especie de pescado a otra y hasta dentro de la misma especie, dependiendo de la época del año, tipo de alimentación, grado de maduración gonadal y sexo. Además, puede presentar variaciones dentro del mismo pez dependiendo de la parte que se utilice (Huss 1998). Debido a que la composición del EP es muy semejante a la de la materia prima (Fernández Herrero et al. 2019a), su valor nutricional también varía según los factores citados. Además dependerá de si se utilizan los peces enteros, los residuos o solo las vísceras, y también del tipo de ensilado químico o biológico (Tabla 5).

Los EP tienen una alta calidad nutricional, similar a la HP (en relación al porcentaje de proteínas en base seca). En general, los ensilados ácidos presentan mayor porcentaje de proteínas, valores cercanos al de una harina Prime que contiene alrededor de $67 \%$ de proteínas, $12 \%$ de grasas, $14 \%$ de cenizas y $10 \%$ de humedad (Cifuentes 2002); mientras que los ensilados biológicos, presentan menor porcentaje de proteínas debido a la presencia de carbohidratos y fibras, lo cual está asociado al material fermentable utilizado.

En cuanto al contenido graso en los EP, éste variará además dependiendo de la presencia o no de vísceras y del tipo de pescado utilizado. El porcentaje de grasa del pescado es muy variado $\mathrm{y}$, dependiendo de la forma como almacenan los lípidos de reserva energética, se clasifican en magros o en grasos. Los pescados magros usan el hígado como su depósito energético (merluza, lenguado) y los grasos (anchoíta, caballa) almacenan los lípidos en células grasas en todas partes del cuerpo (generalmente localizadas en el tejido subcutáneo, en los músculos del vientre y en los músculos que mueven las aletas y cola). Algunas especies que guardan grandes cantidades de lípidos, también la depositan en la cavidad ventral (Huss 1998). Por otro lado, los altos valores de ceniza están relacionados directamente con la alta presencia de estructuras óseas (cabezas y esqueletos).

\section{Valor nutricional de los ensilados}

La composición química del ensilado de pescado es semejante al de la materia prima que le dio origen e incluye proteínas de elevado valor biológico con perfil adecuado de aminoácidos, ácidos grasos poliinsaturados (AGPI) de la serie omega3 (n3) como el EPA (ácido eicosapentaenóico) y el DHA (ácido docosahexaenóico), micronutrientes como vitamina A y $\mathrm{D}$, riboflavina, niacina $\mathrm{y}$ minerales (Anbe 2011).

\section{Las proteinas}

Para evaluar el aporte nutricional de una proteína se utilizan distintos índices, entre los que se incluyen el "score químico" o "cómputo químico" (CQ) y el "índice de eficiencia proteica" (protein efficiency ratio: PER) (Tabla 6). El CQ de un insumo proteico informa sobre la capacidad para satisfacer los requerimientos de aminoácidos esenciales (AAE) que tenga la especie a alimentar respecto de una proteína de referencia (Sgarbieri 1987). El CQ fue aplicado por distintos autores en estudios de nutrición de peces y crustáceos (Bhaskar et al. 2008; Espinosa Chaurand et al. 2013).

Vidotti et al. (2003) hallaron que la lisina, histidina, metionina y fenilalanina están presentes en concentraciones más altas, mientras que la valina y la isoleucina son deficientes en ensilados ácidos $y$, la arginina es deficiente en ensilados fermentados. A su vez, el nivel de triptófano se halló por debajo de los estándares de la NRC (1993) y solo superado en el ensilado ácido de peces de agua dulce enteros, por lo que de acuerdo con el CQ, el triptófano es el aminoácido limitante. También se halló al triptófano como limitante en ensilados de subproductos de Micropogonias furnieri y de Merluccius hubbsi (Fernández Herrero et al. 2017d, 2018). La valina se halló en cantidades 
Tabla 5. Composición química de distintos tipos de ensilados (\% MS).

Table 5. Chemical composition of different types of silage (\% DM).

\begin{tabular}{|c|c|c|c|c|c|}
\hline Materia prima & $\% \mathrm{P}$ & $\% \mathrm{EE}$ & $\% \mathrm{C}$ & $\% \mathrm{HC}$ & Bibliografía \\
\hline Oreochromis niloticus & 33,00 & 12,25 & 25,07 & - & Borghesi (2004) (B) \\
\hline Oreochromis niloticus & 42,53 & 11,94 & 20,64 & 24,89 & Toledo y Llanes Iglesias (2006) (B) \\
\hline \multicolumn{6}{|l|}{$\begin{array}{l}\text { Pseudoplatystoma fasciatum, } \\
\text { Oncorhynchus mykiss }\end{array}$} \\
\hline y Pimelodus groskopfi & 33,01 & 35,74 & 15,28 & 16,14 & Holguin et al. (2009) (B) \\
\hline Cyprinus carpio (carpa) & 54,82 & 9,09 & 12,67 & 23,41 & Sesto (2010) (B) \\
\hline Thunnus albacares & 30,52 & 14,26 & 21,11 & 34,10 & Spanopoulos et al. (2010) (B) \\
\hline Oreochromis sp. & 26,84 & 16,04 & 10,05 & 47,07 & Spanopoulos et al. (2010) (B) \\
\hline Cyprinus carpio (carpa) & 57,39 & 6,93 & 10,59 & ND & Fernández Herrero et al. (2011) (B) \\
\hline Merluccius hubbsi & 63,50 & 5,60 & 11,30 & ND & Góngora (2013) (B) \\
\hline Engraulis anchoita (anchoíta) & 49,41 & 21,35 & 7,92 & ND & Fernández Herrero et al. (2013) (B) \\
\hline Engraulis anchoita (anchoíta) & 48,29 & 12,09 & 7,89 & 31,73 & Fernández Herrero et al. (2015a) (B) \\
\hline Merluccius hubbsi (merluza) & 44,58 & 13,19 & 12,12 & 24,34 & Fernández Herrero et al. (2015b) (B) \\
\hline Micropogonias furnieri (corvina) & 41,27 & 9,91 & 13,45 & 27,99 & Fernández Herrero et al. (2015c) ( B) \\
\hline Merluccius hubbsi (merluza) & 47,90 & 15,80 & 8,70 & - & Fernández Herrero et al. (2016) (B) \\
\hline Arapaima gigas (paiche) & 32,05 & 16,91 & 18,10 & 32,94 & Sosa Espinosa (2017) (B) \\
\hline Merluccius hubbsi (merluza) & 58,23 & 9,40 & 9,90 & 22,47 & Fernández Herrero et al. (2017c) (B) \\
\hline Micropogonias furnieri (corvina) & 41,28 & 15,05 & 16,89 & ND & Fernández Herrero et al. (2017b) (B) \\
\hline Acanthistius patachonicus (mero) & 56,21 & 8,65 & 12,28 & 21,73 & Fernández Herrero et al. (2019a) (B) \\
\hline Cynoscion sp. & 53,79 & 16,80 & 21,13 & - & Seibel y Souza Soares (2003) (Q) \\
\hline Sorgentinia incisan (cornalito) & 61,87 & 14,52 & 27,71 & - & Fernández Herrero et al. (2004) (Q) \\
\hline Aristichthys nobilis & 51,97 & 14,59 & 25,23 & & Llanes Iglesias et al. (2007 b) (Q) \\
\hline Merluccius hubbsi (merluza) & 61.88 & 20,63 & 16,50 & - & Góngora y Ruiz (2008) (Q) \\
\hline Merluccius hubbsi (merluza) & 70,71 & 18,78 & 11,43 & - & Fernández Herrero et al. (2008) (Q) \\
\hline Salilota australis (bacalao criollo) & 74,22 & 9,39 & 17,22 & - & Fernández Herrero et al. (2009) (Q) \\
\hline Sardinella brasiliensis (sardina) & 65,62 & 21,23 & 13,11 & - & Anbe (2011) (Q) \\
\hline Epinephelus malabaricus & 36,06 & 12,24 & 14,04 & - & Ramasubburayan et al. (2013) (Q) \\
\hline Cyprinus carpio (carpa) & 60,74 & 9,12 & 26,85 & - & Viglezzi (2012) (Q) \\
\hline Trachurus murphy & 72,75 & 19,81 & 6,86 & - & Yupanqui Pajuelo (2013) (Q) \\
\hline Acanthistius patachonicus (mero) & 71,56 & 13,28 & 12,70 & - & Fernández Herrero et al. (2017a) (Q) \\
\hline Merluccius hubbsi (merluza) & 64,60 & 18,66 & 16,74 & - & Fernández Herrero et al. (2018) (Q) \\
\hline Merluccius hubbsi (merluza) & 64,00 & 13,10 & 21,66 & - & Fernández Herrero et al. (2019b) (Q) \\
\hline
\end{tabular}

P: proteínas, EE: extracto etéreo, C: cenizas, HC: hidratos de carbono. Ensilados químico (Q) y biológico (B).

deficientes en el ensilado ácido de merluza coincidiendo con Vidotti et al. (2003), mientras que el resto de los aminoácidos están presentes en cantidades suficientes o superior al valor requerido.
El PER es un método fiable que calcula la calidad nutricional de las proteínas en un ensayo in vivo mediante la medición del crecimiento de un animal en estudio (aumento de peso $\mathrm{g}^{-1}$ de proteí- 
Tabla 6. Composición de aminoácidos esenciales (AAE) de ensilados proteicos ( $100 \mathrm{~g}^{-1}$ de proteína) y cómputo químico (CQ). Table 6. Essential amino acids (EAA) composition of protein silage ( $\mathrm{g} 100 \mathrm{~g}^{-1}$ of protein) and chemical count (CQ).

\begin{tabular}{|c|c|c|c|c|c|c|c|c|c|c|c|c|c|c|c|c|c|}
\hline \multirow[b]{2}{*}{ AAE } & \multicolumn{8}{|c|}{ Ensilados } & \multirow[b]{2}{*}{ Ref. } & \multicolumn{8}{|c|}{ CQ } \\
\hline & A & B & $\mathrm{C}$ & $\mathrm{D}$ & $\mathrm{E}$ & $\mathrm{F}$ & G & $\mathrm{H}$ & & A & B & $\mathrm{C}$ & $\mathrm{D}$ & $\mathrm{E}$ & $\mathrm{F}$ & G & $\mathrm{H}$ \\
\hline Treonina & 5,50 & 5,43 & 4,97 & 4,58 & 5,12 & 5,28 & 4,68 & 4,72 & 3,75 & 1,47 & 1,45 & 1,33 & 1,22 & 1,37 & 1,41 & 1,25 & 1,26 \\
\hline Histidina & 3,09 & 2,63 & 5,85 & 5,70 & 3,08 & 2,75 & 2,52 & 2,20 & 1,72 & 1,80 & 1,53 & 3,40 & 3,31 & 1,79 & 1,60 & 1,47 & 1,28 \\
\hline Arginina & 9,19 & 6,45 & 2,19 & 6,11 & 1,80 & 7,72 & 2,49 & 7,27 & 4,20 & 2,19 & 1,54 & 0,52 & 1,45 & 0,43 & 1,84 & 0,59 & 1,73 \\
\hline Metionina & 2,06 & 3,31 & 6,03 & 3,75 & 4,97 & 5,31 & 5,54 & 5,37 & 2,68 & 0,77 & 1,24 & 2,25 & 1,40 & 1,85 & 1,98 & 2,07 & 2,00 \\
\hline Valina & 5,58 & 6,79 & 5,77 & 4,16 & 5,83 & 3,92 & 5,06 & 4,31 & 2,80 & 1,99 & 2,43 & 2,06 & 1,49 & 2,08 & 1,40 & 1,81 & 1,54 \\
\hline Triptofano & 0,09 & 0,08 & 0,65 & 0,66 & 0,87 & 1,34 & 0,61 & 0,43 & 1,00 & 0,09 & 0,08 & 0,65 & 0,66 & 0,87 & 1,34 & 0,61 & 0,43 \\
\hline Fenilalanina & 4,30 & 4,41 & 4,32 & 4,08 & 4,07 & 4,26 & 3,63 & 3,35 & 3,75 & 1,15 & 1,18 & 1,15 & 1,09 & 1,09 & 1,14 & 0,97 & 0,89 \\
\hline Isoleucina & 4,73 & 5,17 & 5,05 & 3,10 & 5,00 & 3,10 & 4,63 & 2,51 & 3,11 & 1,52 & 1,66 & 1,62 & 1,00 & 1,61 & 1,00 & 1,49 & 0,81 \\
\hline Leucina & 8,16 & 9,08 & 8,00 & 7,33 & 9,31 & 7,57 & 6,72 & 6,23 & 3,39 & 2,41 & 2,68 & 2,36 & 2,16 & 2,75 & 2,23 & 1,98 & 1,84 \\
\hline Lisina & 10,57 & 6,79 & 9,16 & 7,9 & 9,92 & 9,09 & 5,94 & 6,77 & 5,12 & 2,06 & 1,33 & 1,79 & 1,54 & 1,94 & 1,78 & 1,16 & 1,32 \\
\hline
\end{tabular}

A: químico de residuos de merluza (Fernández Herrero et al. 2018), B: biológico de residuos de corvina (Fernández Herrero et al. 2017d), C: biológico de residuos de pescado marino (Vidotti et al. 2003), D: químico de residuos de pescado marino (Vidotti et al. 2003), E: biológico de residuos de pescado de agua dulce (Vidotti et al. 2003), F: químico de residuos de pescado de agua dulce (Vidotti et al. 2003), G: biológico de residuos de tilapia (Vidotti et al. 2003), H: químico de residuos de tilapia (Vidotti et al. 2003), Ref.: requerimientos de AAE (en g $100 \mathrm{~g}^{-1}$ de proteína) de tilapia del Nilo (NRC 1993).

na en el alimento); sin embargo, presenta la desventaja de que es un método caro y requiere mucho tiempo (Šližyte et al. 2005). Frente a estas dificultades, Alsmeyer et al. (1974) y Lee et al. (1978) citado por Ovissipour et al. (2009), demostraron que las cantidades relativas de los diversos aminoácidos en los alimentos podrían utilizarse como estimadores confiables de calidad de la proteína real y desarrollaron ecuaciones matemáticas para predecir los valores de PER (Tabla 7).

Fernández Herrero et al. (2017d, 2018) hallaron en EB de subproductos de corvina (M. furnie$r i)$ y EQ de merluza (M. hubbsi) valores de PER similares o mayores a los reportados por Schuchardt (2005) para HP y a los resultados de Ovissipour et al. $(2009,2010)$ en hidrolizados de vísceras de atún (Thunnus albacares) y esturión persa (Acipenser persicus) (Tabla 8).

Este tipo de índices (CQ y PER) son muy útiles si los EP son considerados como un ingrediente en dietas equilibradas, evidenciando que, a pesar de deficiencias menores en ciertos aminoácidos esenciales, los ensilados no pierden su valor nutricional.

\section{Los lípidos}

En los EP la composición de ácidos grasos (AG) es muy variable dependiendo directamente de la materia prima utilizada en su elaboración. La mayoría de los estudios sobre la composición de AG de los aceites de pescado se refieren a partes comestibles; sin embargo, existen muchos trabajos sobre ensilados de subproductos pesqueros que han determinado la composición de los ácidos grasos y además han utilizado como criterio de evaluación de la calidad de las grasas la relación entre ácidos grasos poliinsaturados y los saturados.

En los estudios revisados de EP ácidos y biológicos de especies marinas y dulceacuícolas (Tabla 
Tabla 7. Ecuaciones para el cálculo del índice de eficiencia proteica (PER). Tomado de Alsmeyer et al. (1974) y Lee et al. (1978) citado por Ovissipour et al. (2009).

Table 7. Equations for calculating the protein efficiency ratio (PER). Taken from Alsmeyer et al. (1974) and Lee et al. (1978) cited in Ovissipour et al. (2009).

\begin{tabular}{ll}
\hline $\mathrm{N}^{\mathrm{o}}$ de ecuación & \multicolumn{1}{c}{ Ecuación } \\
\hline 1 & $-0,684+0,456[\mathrm{Leu}]-0,047[\mathrm{Pro}]$ \\
2 & $-0,468+0,454[\mathrm{Leu}]-0,104[\mathrm{Tyr}]$ \\
3 & $-1,816+0,435[\mathrm{Met}]+0,780[\mathrm{Leu}]+0,211[\mathrm{His}]-0,944[\mathrm{Tyr}]$ \\
4 & $0,08084\left[\mathrm{X}_{7}\right]-0,1094$ \\
5 & $0,06320\left[\mathrm{X}_{10}\right]-0,1539$ \\
\hline
\end{tabular}

$\mathrm{X}_{7}=\mathrm{Thr}+\mathrm{Val}+\mathrm{Met}+\mathrm{Ile}+\mathrm{Leu}+\mathrm{Phe}+\mathrm{Lys} ; \mathrm{X}_{10}=\mathrm{X}_{7}+\mathrm{His}+\mathrm{Arg}+\mathrm{Tyr}$

Tabla 8. Índice de eficiencia proteica (PER) de ensilado de merluza (Merluccius hubbsi) y corvina (Micropogonias furnieri); harina de pescado (HP) e hidrolizados de atún (Thunnus albacares) y esturión (Acipenser persicus).

Table 8. Protein efficiency ratio (PER) of silage of hake (Merluccius hubbsi) and croaker (Micropogonias furnieri); fish meal (HP) and hydrolyzed tuna (Thunnus albacares) and Sturgeon (Acipenser persicus).

\begin{tabular}{|c|c|c|c|c|c|}
\hline \multirow[b]{2}{*}{$\mathrm{N}^{\mathrm{o}}$ de ecuación (Tabla 7) } & \multicolumn{5}{|c|}{ PER } \\
\hline & Merluza & Corvina & Atún & Esturión & HP \\
\hline 1 & 2,80 & 2,72 & - & 2,40 & 2,68 \\
\hline 2 & 3,02 & 3,44 & 2,89 & 2,52 & 2,74 \\
\hline 3 & 4,15 & 5,34 & 5,38 & 6,45 & 3,02 \\
\hline 4 & 3,20 & 3,20 & 2,85 & 3,16 & 2,84 \\
\hline 5 & 3,34 & 3,14 & 3,33 & 3,14 & 2,87 \\
\hline
\end{tabular}

9), el ácido graso saturado (AGS) más abundante fue el palmítico (C16:0), con un valor mínimo de 16,14\% (Cyprinus carpio; Crexi et al. 2009) y un valor máximo de 30,16\% (Acanthistius patachonicus; Fernández Herrero et al. 2019a). El ácido palmítico es reconocido como una fuente de energía metabólica durante el crecimiento y formación de huevos en los peces (Özyurt et al. 2015). Otros AGS con una amplia variación en su concentración son el ácido mirístico (C14:0), con un valor mínimo de $2,54 \%$ (M. hubbsi; Fernández Herrero et al. 2017e) y un valor máximo de 14,12\% (Equulite kluzingeri; Özyurt et al. 2015), y el ácido esteárico (C18:0) cuyo intervalo se halla entre 2,45\% (M. hubbsi) hasta 8,67\% ( $E$. kluzingeri). En cuanto a los ácidos grasos monoinsaturados (AGMI), el más abundante identificado en los ensilados analizados fue el ácido oleico (C18:1n9), con valores que van desde $8,9 \%$ (E. kluzingeri) a $32,67 \%$ en tilapia (Vidotti et al. 2011). El ácido graso poliinsaturado (AGPI) más abundante en los ensilados fue el DHA, excepto en tilapia y carpa, donde el ácido linoleico llega a valores entre 9,47 y $10,35 \%$ y, el ácido linolénico se encontró entre 0,81 a 7,17\% (ensilado de tilapia y carpa, respectivamente). 
Tabla 9. Perfil de ácidos grasos en ensilados de distintas especies de peces

Table 9. Profile of fatty acids of silage from different fish species.

Ensilados

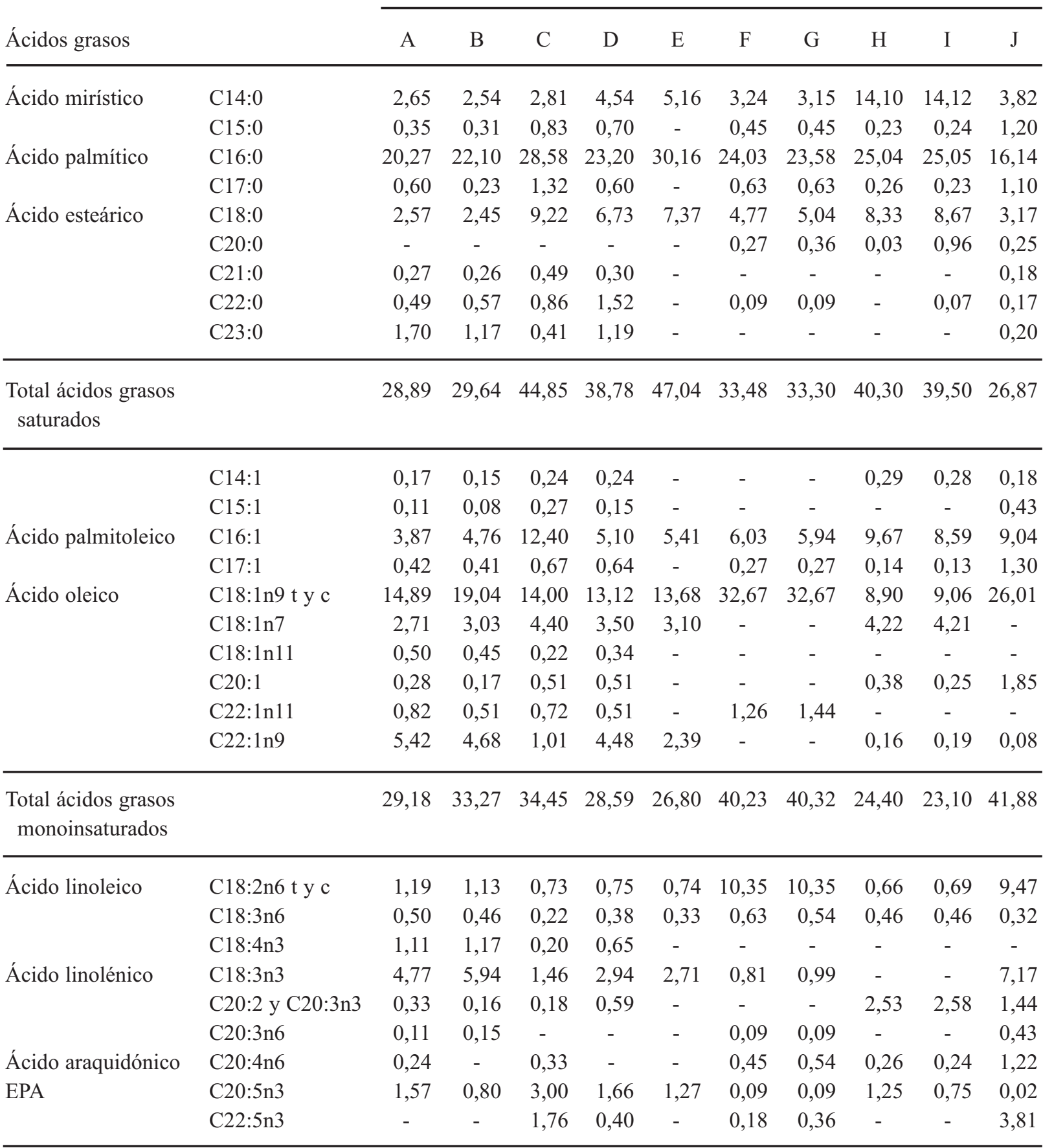


Tabla 9. Continuación.

Table 9. Continued.

Ensilados

\begin{tabular}{|c|c|c|c|c|c|c|c|c|c|c|c|}
\hline \multirow{2}{*}{\multicolumn{2}{|c|}{ Ácidos grasos }} & & & & & & & & & & \\
\hline & & A & $\mathrm{B}$ & $\mathrm{C}$ & $\mathrm{D}$ & $\mathrm{E}$ & $\mathrm{F}$ & G & $\mathrm{H}$ & I & $\mathrm{J}$ \\
\hline DHA & $\mathrm{C} 22: 6 \mathrm{n} 3$ & 19,69 & 18,60 & 4,80 & 11,62 & 9,34 & 0,27 & 0,45 & 7,94 & 9,07 & 1,20 \\
\hline $\begin{array}{l}\text { Total ácidos grasos } \\
\text { poliinsaturados }\end{array}$ & & 29,52 & 28,40 & 12,68 & 18,99 & 14,39 & 12,87 & 13,41 & 14,30 & 15,10 & 25,50 \\
\hline $\mathrm{n} 3 / \mathrm{n} 6$ & & 13,47 & 15,33 & 8,91 & 15,81 & 12,45 & 0,12 & 0,16 & 8,49 & 8,92 & 1,15 \\
\hline
\end{tabular}

A: biológico de residuos de merluza (Fernández Herrero et al. 2017c), B: químico de residuos de merluza (Fernández Herrero et al. 2017e), C: biológico de residuos de corvina (Fernández Herrero et al. 2017b), D: químico de residuos de mero (Fernández Herrero et al. 2017a), E: biológico de residuos de mero (Fernández Herrero et al. 2019a), F: químico de residuos de tilapia (Vidotti et al. 2011), G: biológico de residuos de tilapia (Vidotti et al. 2011), H: químico de residuos de pez marino (Özyurt et al. 2015), I: biológico de residuos de pez marino (Özyurt et al. 2015), J: químico de residuos de carpa (Crexi et al. 2009).

\section{Criterios para evaluar la calidad del ensilado de pescado}

La calidad del ensilado de pescado está directamente relacionada a la frescura de la materia prima, la cual debe procesarse lo antes posible. Las enzimas y bacterias endógenas pueden degradar rápidamente el material crudo impactando significativamente en la calidad del producto final. Los parámetros usualmente utilizados para la evaluación de la calidad son: histamina, nitrógeno básico volátil total (NBVT), grado de oxidación de los lípidos (TBARS) y la composición microbiológica, entre otros.

La formación de histamina es el resultado de una inadecuada preservación del pescado. En general, se hallan bajos valores de histamina en los ensilados, lo cual podría asociarse al poder bactericida que presenta el medio ácido (ya sea por ácido agregado o producido). En HP se establecen niveles promedios máximos de histamina según el tipo de harina: super prime (250 ppm), prime $(600 \mathrm{ppm})$ y estándar (por encima de 600 ppm) (Fernández Jeri 2002).
La determinación del NBVT es una de las pruebas analíticas más ampliamente utilizadas para evaluar el grado de frescura del pescado y los productos derivados. En la Argentina, no se cuenta con normas que establezcan valores permitidos de NBVT en subproductos de origen acuático $\mathrm{y}$, debido a que los EP suelen utilizarse como insumo en alimentos balanceados, se han tomado como referencia los valores para HP que según Belli Contreras (2009) se clasifican en: buenas 115-117 mg N $100 \mathrm{~g}^{-1}$, contaminada 450$500 \mathrm{mg} \mathrm{N} \mathrm{N}_{2} 100 \mathrm{~g}^{-1}$ y muy contaminada $1.100 \mathrm{mg}$ $\mathrm{N}_{2} 100 \mathrm{~g}^{-1}$.

En los EP se han reportado distintos valores de NBVT dependiendo de la materia prima utilizada, tipo de ensilado (químico o biológico) y el tiempo de almacenamiento (Tabla 10). González y Marín (2005) obtuvieron valores entre 172,9-157,4 mg $\mathrm{N}_{2} 100 \mathrm{~g}^{-1}$ en EB con residuos de sardina a los 60 días de almacenamiento. Dapkevicius et al. (2007) informaron resultados de $18 \mathrm{mg} \mathrm{N}_{2} 100 \mathrm{~g}^{-1}$ en ensilado químico de Trachurus picturatus a los 21 días. Fernández Herrero et al. $(2008,2018)$ en EQ de merluza obtuvieron valores entre 65,97-74,86 
Tabla 10. Valores de NBVT y TBAR en distintos ensilados. Table 10. NBVT and TBAR values in different silages.

\begin{tabular}{|c|c|c|c|c|}
\hline Materia prima & Ensilado & $\begin{array}{c}\text { NBVT } \\
\left(\mathrm{mg} \mathrm{N}_{2} 100 \mathrm{~g}^{-1}\right)\end{array}$ & $\begin{array}{c}\text { TBAR } \\
\left(\mathrm{mg} \mathrm{MDA} \mathrm{kg}^{-1}\right)\end{array}$ & Bibliografía \\
\hline Cyprinus carpio & Biológico & $97,24-96,44$ & $2,79-2,88$ & Sesto (2010) \\
\hline Cyprinus carpio & Químico & 75,34 & & Vigliezzi (2012) \\
\hline Engraulis anchoita & Biológico & $188,59-231,51$ & $4,04-4,84$ & Fernández Herrero et al. (2013) \\
\hline Merluccius hubbsi & Biológico & 162,37 & 5,82 & Fernández Herrero et al. (2015b) \\
\hline Micropogonias furnieri & Biológico & $104,81-102,70$ & $13,12-13,69$ & Fernández Herrero et al. (2017b) \\
\hline Acanthisthius patachonicus & Químico & $81,21-112,81$ & & Fernández Herrero et al. (2017a) \\
\hline Merluccius hubbsi & Químico & $99,68-103,52$ & & Fernández Herrero et al. (2018) \\
\hline Acanthisthius patachonicus & Biológico & $111,98-145,54$ & & Fernández Herrero et al. (2019a) \\
\hline
\end{tabular}

mg $\mathrm{N}_{2} 100 \mathrm{~g}^{-1}$ a los 15 días de almacenamiento $\mathrm{y}$, entre 99,68-103,52 mg $\mathrm{N}_{2} 100 \mathrm{~g}^{-1}$ a los 30 días; mientras que en ensilado biológico de merluza a los 30 días, 162,37 mg N $100 \mathrm{~g}^{-1}$ (Fernández Herrero et al. 2015b). Fernández Herrero et al. (2013, 2017a, 2017b, 2019a) también trabajaron con ensilados químicos y biológicos de otras especies como corvina, anchoíta y mero, hallando distintos valores de NBVT. Por su parte, Sesto (2010) halló en ensilado biológico de carpa valores entre 97,24-96,44 mg $\mathrm{N}_{2} 100 \mathrm{~g}^{-1}$ a los 30 días, mientras que Viglezzi (2012) trabajando en ensilado químico de carpa determinó $96 \mathrm{mg} \mathrm{N}_{2} 100 \mathrm{~g}^{-1}$ a los 20 días de almacenamiento.

Para estimar como se degradan los lípidos durante el proceso de ensilado se puede determinar el TBARS (thiobarbituric acid reactive substances), el cual se toma como un indicador del grado de oxidación lipídica y formación de productos secundarios de oxidación tales como aldehídos, cetonas y alcoholes. El valor de TBARS que indica buena calidad del músculo de pescado es alrededor de $5 \mathrm{mg}$ MDA kg-1, pero se acepta para el consumo humano valores de hasta $8 \mathrm{mg}$ MDA kg-1 (Osorio Contreras 2014; Rodríguez y Rojas 2014). Para una HP el valor de TBARS puede considerarse normal hasta $8 \mathrm{mg} \mathrm{MD} \mathrm{kg}^{-1} \mathrm{y}$ altamente oxidado a partir de $15 \mathrm{mg}$ MDA kg-1
(Cruz Suárez et al. 2000). Nuevamente, el grado de oxidación de los lípidos contenidos en el EP dependerá de la materia prima, tipo de ensilado, tiempo de almacenamiento y uso o no de antioxidantes. Sesto (2010) trabajó con EB de carpa y halló valores entre 2,79-2,88 mg MDA kg-1 a los 30 días de almacenamiento. Viglezzi (2012) en EQ de carpa obtuvo valores cercanos a $4,50 \mathrm{mg}$ MDA kg-1. Por su parte, Fernández Herrero et al. (2013, 2015b, 2017b) en EB hallaron valores entre 4,04-4,84 mg MDA kg-1 para anchoíta, $5,82 \mathrm{mg}$ MDA kg-1 para merluza y entre $13,12-$ 13,69 $\mathrm{mg} \mathrm{MDA} \mathrm{kg}^{-1}$ para corvina (Tabla 10).

Con respecto a los análisis microbiológicos, éstos permiten evaluar la inocuidad de los EB obtenidos y la aplicación de una buena práctica de elaboración. Es importante señalar que la Argentina no cuenta con normas que establezcan valores permitidos de microorganismos en residuos de origen acuático. Sin embargo, Bello (1994) y Huss (1998) consideran aceptables valores por

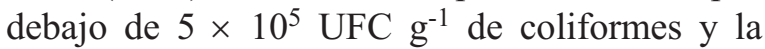
ausencia de Salmonella spp. en productos para la alimentación animal. Por su parte, Fernández Herrero et al. (2017a) tomaron como valores de referencia para bacterias aerobias mesófilas totales el nivel máximo permitido para pescado fresco $\left(10^{6} \mathrm{UFC}^{-1}\right)$ e inferiores al límite máximo de 
$5 \times 10^{5} \mathrm{UFC} \mathrm{g}^{-1}$ para pescado congelado de acuerdo con International Commission on Microbiological Specification for Foods (ICMSF 1983); y para hongos y levaduras los rangos permitidos por la normativa del Instituto Colombiano Agropecuario (ICA 1999) para alimentos de animales en Colombia $\left(0,05 \times 10^{5}\right.$ a $\left.1,0 \times 10^{5} \mathrm{UFC} \mathrm{g}^{-1}\right)$. Los valores de histamina, NBVT, TBARS y el perfil microbiológico nos permiten definir la calidad de un ensilado para considerarlo en su uso posterior como insumo en alimentos balanceados.

\section{Evaluación sensorial}

Durante la maduración de los EP se producen cambios en cuanto a su consistencia, olor y color (Tabla 11). Se observa un aumento gradual de la licuefacción, pasando de una mezcla homogénea de textura pastosa con apenas exudado de líquido, a una forma líquida con partículas pequeñas. El color presenta leves cambios: al inicio del proceso el color es beige-rojizo (semejante a carne picada) y cambia a beige claro-oscuro, etc. Por último, el olor comienza siendo a pescado fresco, pasa a ácido o vinagre en los EQ, mientras que en los $\mathrm{EB}$ puede tener olor a queso suave, frutas, oporto.

\section{Potenciales aplicaciones de los ensilados de pescado}

\section{Como insumo en alimentación}

El insumo de mayor importancia en producción animal es la HP por su alto contenido proteico (60-72\%). La proporción de HP en los alimentos para animales terrestres podría oscilar entre 1 y $5 \%$. Sin embargo, para el salmón de cultivo la cantidad puede ser mucho mayor (20-30\%), ya que no hay restricciones de sabor en el producto final. Debido a su alto costo en el mercado se demandan fuentes alternas de proteína (Castillo et al. 2019; FAO 2020).

El EP es una alternativa menos costosa a la harina y al aceite de pescado, y se utiliza cada vez más como insumo para piensos en la industria de alimentos para animales de cría y en la acuicultura. Su uso también reduciría los costos en la formulación del pienso y consecuentemente los costos de producción de peces, ya que los gastos con el pienso representan aproximadamente el $60 \%$ del costo total (Balsinde et al. 2003; Vidotti et al. 2003; Borghesi et al. 2008). Es una excelente fuente de proteínas, posee gran digestibilidad y es un producto de alto valor biológico para la alimentación animal. Además, el EB de pescado presenta beneficios antibacterianos, antioxidantes y es una fuente posible de probióticos (Özyurt et al. 2017; Ramírez Ramírez et al. 2018).

Diversos autores evaluaron la utilización del EP en la alimentación de distintos animales de cría. En rumiantes, Lira Sánchez (2010) evaluó el efecto de la inclusión del EB en la dieta sobre la composición y producción de leche de vacas en un sistema de manejo de doble propósito y concluyó que vacas en lactación pueden consumir hasta $2 \mathrm{~kg} \mathrm{~d}^{-1} \mathrm{de} \mathrm{EB}$ sin cambios en la producción de leche pero con mayor contenido de proteína y menos grasa. Por su parte Parisuaña Callata et al. (2018) determinaron el efecto del nivel de inclusión de ensilado de subproductos de trucha en tres proporciones $(0,4$ y 8\%) en la ración de ovinos.

Tabla 11. Descriptores utilizados para la evaluación sensorial de la maduración del ensilado. Table 11. Descriptors used for the sensory evaluation of silage maturation.

Color

Olor

Consistencia

Según su intensidad
Beige, beige oscuro, marrón, rojizo, grisáceo, otros

Yogur, queso, frutas, vísceras, vinagre, ácido, oporto, otros

Cremoso, pastoso, levado, con burbujas de $\mathrm{CO}_{2}$, con hongos en superficie, otros Ligero, definido y fuerte 
Los resultados indicaron que el ensilado en las raciones de engorde de ovino mejora el rendimiento productivo sin afectar el sabor de la carne. Anuraj et al. (2014) trabajaron con cerdos Large White Yorkshire incorporando en su dieta distintos porcentajes $(10,50$ y $100 \%)$ de ensilado de subproductos de atún. Los animales no presentaron diferencias con respecto a su ganancia diaria promedio, peso corporal quincenal y conversión alimenticia. Por su parte, Sánchez et al. (2013) estudiaron el efecto del EB de subproductos del procesamiento de Penaeus vannamei en tres niveles de inclusión $(0,10,15$ y $20 \%)$ en marranas gestantes y lactantes evaluadas independiente. El uso de ensilado permitió su incremento en peso en la etapa de gestación. Las mejores conversiones alimenticias se obtuvieron en la etapa de gestación para los tres niveles de tratamiento y aumenta la digestibilidad en las dietas. Góngora y Ruiz (2008) observaron en la alimentación de cerdos en crecimiento el rendimiento de un alimento experimental formulado con $50 \%$ de EQ de subproductos de $M$. hubbsi como insumo proteico. Concluyeron que el EQ se puede emplear para mejorar la conversión alimentaria, con posibilidad de reducir costos en la cría de porcinos en crecimiento.

En aves, De Souza Batalha (2017) evaluó el efecto de la harina de EQ producido a partir de subproductos de Pirarucu (Arapaima gigas) en la alimentación de gallinas ponedoras. Los resultados indicaron que este EQ se puede incluir en forma de harina al nivel del $3 \%$ en sus dietas, presentando buena digestibilidad de nutrientes y potencial para utilizarse como fuente de energía. Valenzuela et al. (2015) analizaron el efecto del uso de EQ de salmón co-secado con afrecho de trigo en dietas de pollos (broiler). Utilizaron cuatro porcentajes de inclusión $(4,8,12$ y $15 \%)$ y concluyeron que el ensilado puede convertirse en una importante contribución a la alimentación de estos pollos y una alternativa a los concentrados proteicos que existen actualmente en el mercado. También observaron que su incorporación en die- tas de los pollos hasta $15 \%$ al día 32 de vida de los animales no genera efectos sobre los parámetros de rendimiento productivo como tampoco en las características sensoriales de la carne de pechuga. Por su parte, Muhammed et al. (2015) observaron los efectos de la inclusión (entre 1 y $2 \%$ ) de aceite de pescado (FO) obtenido a partir del EB de subproductos del procesamiento de la carpa india rohu (Labeo rohita) y de catla (Catla catla) en la alimentación de pollos de engorde. Las características de rendimiento de la carne de pollos de engorde no difirieron entre tratamientos. La alimentación con FO redujo la concentración de colesterol total en suero, carne e hígado en comparación con los controles, pero no hubo diferencias en la concentración de triglicéridos entre los tratamientos. Se observaron concentraciones aumentadas de EPA y DHA en suero, hígado y carne a medida que aumentó la concentración de FO. El estudio demuestra claramente el valor del aceite obtenido de EB. Ramírez Ramírez et al. (2013) estudiaron la utilización de EB con diferentes niveles de inclusión $(0,10,20$ y $30 \%$ ) en la alimentación de codornices (Coturnix coturnix japonica) y determinaron que el uso de EB en sus dietas podría ofrecer una buena alternativa para la utilización de subproductos de pescado como componente alimenticio para la mejora de la composición de ácidos grasos en la carne.

En acuicultura, Terrones España y Reyes Avalos (2018) evaluaron el efecto de dietas con EB de subproductos del molusco bivalvo (Argopecten purpuratus) en el crecimiento del camarón Cryphiops caementarius y tilapia Oreochromis niloticus en cocultivo intensivo. Emplearon tres dietas experimentales $(25,50$ y $75 \%$ de ensilado) y una dieta control. El crecimiento del camarón fue similar entre tratamiento, mientras que el crecimiento de tilapia fue mayor con 25 y $50 \%$ de ensilado. La tasa de conversión alimenticia fue baja $(1,5$ a 1,7$)$ en camarón y alta $(1,9$ a 2,1$)$ en tilapia hasta con $50 \%$ de ensilado. Tanuja et al. (2017) trabajaron con dietas isonitrogenadas que contenían $0,2,5,5$ y $10 \%$ de EQ de subproductos 
de carpa de agua dulce en la alimentación de alevines de rohu (Labeo rohita). Los resultados del estudio no indicaron diferencias en el aumento de peso, tasa de crecimiento específico, supervivencia y tasa de conversión alimenticia. El coeficiente de digestibilidad aparente de materia seca y proteína fue mayor para alimento con $10 \%$ de ensilado. La inclusión de EP a un nivel del 5\% resultó en una reducción del $14,31 \%$ en el costo del alimento $\mathrm{kg}^{-1}$ de aumento de peso en los alevines de rohu. Perea Román (2016) estudió el valor nutricional de ensilados de subproductos de trucha arco iris (O. mykiss) en la alimentación de tilapia roja (Oreochromis spp). Consideró que el EQ puede ser una alternativa de alta calidad nutricional para la alimentación de tilapia roja debido al buen contenido de nutrientes y a la alta digestibilidad. Sousa et al. (2016) analizaron los parámetros de crecimiento de alevines de Brycon amazonicus sometidos a dietas con diferentes niveles de reemplazo de HP por EB $(0,10,20$ y $30 \%)$ y encontraron que la HP se puede sustituir por $10 \%$ por EB. Ramasubburayan et al. (2013) prepararon dietas con EQ de subproductos de pescado (con distinto porcentaje de ácido fórmico) para alevines de Cyprinus carpio y hallaron que con la dieta de ensilado ácido al $2 \%$ de ácido fórmico, los alevines tuvieron mayor ganancia de peso, tasa específica de crecimiento y un aumento significativo en los componentes bioquímicos. Llanes Iglesias et al. (2012) evaluaron el efecto de dos dietas semi-húmedas formuladas con EQ y EB de subproductos del fileteado de tilapias como única fuente de proteína animal en la alimentación de alevines de tilapias rojas (Oreochromis niloticus x $O$. mossambicus). La menor digestibilidad de la proteína se presentó en la dieta con EB $(86,8 \%)$, la que difirió del EQ $(89,4 \%)$ y el control $(88,7 \%)$. No hubo diferencias en los pesos finales, conversión alimentaria y eficiencia proteica entre los peces que consumieron EP y HP. La supervivencia fue alta para todos los tratamientos. Es así que los ensilados de subproductos del fileteado de tilapias representan una alternativa de alimentación para los cultivos de esta especie.
Wicki et al. (2012) estudiaron el efecto de dos dietas que contienen EQ de pescado en lugar de HP, la primera ofrecida como dieta seca (20\% EQ) y la segunda como dieta húmeda (40\% EQ), en el ciclo final de cultivo de pacú (Piaractus mesopotamicus). Hallaron que el pacú acepta fácilmente la dieta húmeda con aumento de peso en comparación con la dieta seca, y consideraron que es posible cultivar pacú con alimento húmedo de elaboración propia sin HP con un crecimiento similar al de los alimentados con dieta seca.

\section{Como fertilizante}

Los EP pueden utilizarse como fertilizantes en agronomía o medio nutritivo para el cultivo de microalgas. Como medio nutritivo para microalgas, Fernández Herrero et al. (2019c) evaluaron el crecimiento y la calidad nutricional del cultivo de Nannochloropsis oculata empleando tres medios de cultivo diferentes: EB; C (Conway, reactivos pro-análisis) y $\mathrm{F}$ (fertilizante agroindustrial). Como resultado luego de 10 días de cultivo, el tratamiento $\mathrm{EB}$ registró las más altas densidades celulares, seguido del tratamiento $\mathrm{C}$ y por último el $\mathrm{F}$, no hallándose diferencias entre tratamientos. Concluyeron que el empleo de ensilado como medio nutritivo para el cultivo de $N$. oculata permite un buen crecimiento y concentraciones similares a las obtenidas con medios analíticos. Resultados similares fueron hallaron por Sánchez Torres et al. (2008), quienes cultivaron la microalga $N$. oculata en siete diferentes medios de cultivo (T1, Guillard F/2, T2, Yashima y T3-T6, cuatro medios basados en EP, y T7: HP). Los medios basados en EP fueron dos con diferentes ensilados (hidrolizados y no-hidrolizado) y dos por enriquecimiento del medio Yashima con ensilado nohidrolizado en diferentes concentraciones. El mejor de los tratamientos experimentales fue el del medio basado en EP no-hidrolizado (T6), no encontrándose diferencias en la productividad máxima de este cultivo comparado con la del medio Yashima. Se evaluó la calidad nutricional de la biomasa de $N$. oculata obtenida como ali- 
mento vivo para el rotífero Brachionus plicatilis y se encontró que el tratamiento T6 obtuvo un mayor índice de fecundidad en comparación al tratamiento T2, lo que es un indicador de buena calidad nutricional. El medio basado en EP mostró una alta producción, bajo costo y buena calidad nutricional para la producción de microalgas. Por su parte, Abdulsamad y Varghese (2017) trabajaron con la microalga Scenedesmus sp. cultivada con EP para estudiar los efectos de diferentes concentraciones sobre su crecimiento y las características bioquímicas (proteínas, carbohidratos y lípidos). Hallaron que el EP con una concentración del $12 \%$ fue más eficaz para el crecimiento y la producción de biomasa de Scenedesmus sp. y, en el cultivo masivo, encontraron una mayor producción de proteína, carbohidratos y lípidos utilizando un $9 \%$ de EP, demostrando que las microalgas pueden ser cultivadas utilizando el EP. Como fertilizante en agronomía, Ulfah Karim et al. (2015) estudiaron la eficacia del ensilado líquido de pescado (LFS) como abono orgánico sobre la calidad poscosecha de pak choy (col de origen asiático). Los tratamientos con LFS se prepararon en cinco concentraciones diferentes $(1,0 ; 2,5 ; 5,0 ; 7,5 \mathrm{y}$ $10,0 \%$ ). Cada tratamiento se comparó con la planta fertilizada con fertilizante comercial (N-P-K 15:15:15) utilizando el nutriente recomendado por hectárea. Los resultados mostraron que LFS al $5,0,7,5$ y $10,0 \%$ produjo un crecimiento de la planta, rendimiento, contenido de pigmento y calidad poscosecha similares a la planta fertilizada con fertilizantes comerciales. Además, recomiendan utilizar 5,0\% LFS ya que es más económico en comparación con 7,5 y 10,0\%.

\section{CONCLUSIONES}

Para el aprovechamiento y valorización de los subproductos pesqueros, el ensilado de pescado es una alternativa a la HP por ser un proceso de fácil elaboración y que no exige alta inversión, obte- niéndose un producto de buena calidad nutricional y microbiológicamente estable, a la vez que se reducen los problemas de contaminación ambiental y disposición de residuos sólidos. La escala de producción es adaptable a los volúmenes de captura y puede ser aplicado tanto a la pesca industrial, artesanal y a la acuicultura.

La composición química del ensilado de pescado es semejante al de la materia prima que le dio origen e incluye proteínas de elevado valor biológico con perfil adecuado de aminoácidos y ácidos grasos poliinsaturados (AGPI) de la serie omega3 (n3), como el EPA (ácido eicosapentaenoeico) y el DHA (ácido docosahexaenoico). Puede usarse como ingrediente de ración en la industria de alimentos para animales de cría y en la acuicultura o eventualmente como fertilizante. El ensilado de pescado es un valioso ingrediente para los alimentos con características únicas que han demostrado mejorar las cualidades de los alimentos para animales y peces cultivados, a la vez que permitiría disminuir los costos de alimentación y, en consecuencia, los costos de producción de peces, ya que la alimentación corresponde aproximadamente al $60 \%$ de los gastos totales de la producción.

Contribución INIDEP Nº 2239.

\section{BIBLIOGRAFÍA}

Abdulsamad JK, Varghese SA. 2017. Effects of fish silage on growth and biochemical characteristics of fresh water microalga Scenedesmus sp. MB 23. Agric Nat Resour. 51 (4): 235-242.

Alsmeyer RH, Cunningham AE, Happich ML. 1974. Equations predicting PER from amino acid analysis. Food Technol. 28 (7): 34-40.

ANBE L. 2011. Prospecção de componentes bioativos em resíduos do processamento do pescado visando a sustentabilidade da cadeia produtiva [tesis de maestría]. Sao Paulo: Escuela Superior de Agricultura Luiz de Queiroz, Universidad de Sao Paulo. 135 p. 
Anuraj KS, Sreeparvathy M, Shyama K, Dipu MT, HARI R. 2014. Dried tuna waste silage as an alternate protein source for swine feeding. Ind J Sci Res Tech. 2 (3): 49-52.

Areche N, Berenz Z, Leon G. 1992. Desarrollo de ensilado de residuo de pescado utilizando bacterias lácticas de yogurt en engorde. En: Segunda consulta de expertos sobre tecnología de productos pesqueros en América Latina. 11-15 de diciembre de 1989. FAO Informe de Pesca. 441: 51-63.

Argentina. 2020a. Ministerio de Agricultura, Ganadería y Pesca. 2020. Desembarques de capturas marítimas totales - por especie y mes (t). 2019. [consultado 7 julio 2020]. https://www.magyp.gob.ar/sitio/areas/pesca maritima/desembarques/lectura.php?imp $=1 \& \mathrm{t}$ abla=especie_mes_2019.

Argentina. 2020b. Ministerio de Agricultura, Ganadería y Pesca. 2020. Pesquerías continentales de la Argentina. [consultado 9 noviembre 2020]. https://www.magyp.gob.ar/sitio/areas/ pesca_continental/estadisticas.

Baldovino Pacce MF, Lujambio Genta SM, Balzani Pujo L. 2011. Hidrolizados proteicos de pescado obtenidos por métodos biológicos [tesis doctoral]. Montevideo: Facultad de Veterinaria, Universidad de la República. 33 p.

Balsinde RM, Fraga CI, Galindo LJ. 2003. Inclusión de ensilado de pescado como alternativa en la elaboración de alimento extruido para el camarón de cultivo (Litopenaeus schmitti). II Congreso Iberoamericano Virtual de Acuicultura. La Habana: Centro de Investigaciones Pesqueras (CIVA). p. 303-309.

Belli Contreras JE. 2009. Estabilidad aeróbica y día óptimo de uso del ensilado biológico de pescado para la alimentación animal [tesis veterinario]. Veracruz: Facultad de Medicina Veterinaria y Zootecnia, Universidad Veracruzana. 99 p.

Bello R. 1994. Experiencias con ensilado de pescado en Venezuela. En: Taller tratamiento y utilización de desechos de origen animal y otros desperdicios en la ganadería. FAO. Habana. Cuba. Del 5 al 8 de Septiembre. [consultado 7 julio 2020]. http://www.fao.org/ ag/aga/agap/frg/APH134/cap1.htm.1994.

BERENZ Z. 1994. Utilización del ensilado de residuos de pescado en pollos. En: Taller Tratamiento y utilización de desechos de origen animal y otros desperdicios en la ganadería. FAO. La Habana. Cuba. Del 5 al 8 de Septiembre. [consultado 7 julio 2020]. http:// www.fao.org/ag/AGa/AGAP/FRG/APH134/ cap2.htm.

Berenz Z. 1997. Procedimiento de ensilado de pescado. En: XII Curso Internacional de Tecnología de procesamiento de productos pesqueros. 13 de Enero al 7 de Marzo de 1997. Instituto Tecnológico Pesquero del Perú (ITP). Callao. 39 p.

Bhaskar N, Benila T, Radha C, Lalitha RG. 2008. Optimization of enzymatic hydrolysis of visceral waste proteins of Catla (Catla catla) for preparing protein hydrolysate using a commercial protease. Bioresour Technol. 99 (2): 335-343.

BorgHESI R. 2004. Avaliação físico-química e biológica das silagens ácida, biológica e enzimática elaboradas com descarte e resíduo do beneficiamento da tilápia do nilo (Oreochromis niloticus) [tesis de maestría]. Piracicaba: Escola Superior de Agricultura Luiz de Queiroz, Universidade de São Paulo. 108 p.

Borghesi R, Portz L, OetTerer M, Cyrino JeP. 2008. Apparent digestibility coefficient of protein and aminoacids of acid, biological and enzymatic silage for Nile tilapia (Oreochromis niloticus). Aquacul Nutr. 14: 242-248.

Botello AL. 2005. Utilización de diferentes ensilados químicos de pescado en la alimentación de alevines del pez gato africano (Clarias gariepinus Burchell, 1822) [tesis de maestría]. La Habana: Centro de Investigaciones Marinas, Universidad de La Habana.

Botello Al, Toledo Pérez J, García Galano 
T, Llanes Iglesias J, Lazo de la Vega TorNÉS J. 2010. Conservación in vitro de tres ensilajes de pescado (Opisthonema oglinum). Caracterización físico-química. Revista Electrónica Granma Ciencia. 14 (1): 1-10.

Castillo García We, Sánchez Suárez HA, OchoA Mogollón GM. 2019. Evaluación del ensilado de residuos de pescado y de cabeza de langostino fermentado con Lactobacillus fermentus aislado de cerdo. Rev Inv Vet Perú. 30 (4): 1456-1469.

Churacutipa Mamani M. 2016. Obtención de un ensilado biológico a partir de residuos de trucha (Oncorhyncus mykiss) [tesis ingeniería]. Puno: Facultad de Ciencias Agrarias, Universidad Nacional del Altiplano. 103 p.

Cifuentes A. 2002. Factores de calidad en harina de pescado para su empleo en la alimentación de salmónidos. En: Curso de Ciencia y Tecnología de los Productos Pesqueros. Aprovechamiento integral de los recursos del mar. Mar del Plata. Argentina. 2, 3 y 4 de Mayo de 2002.

Cipriano Salazar M, Abrego Salgado NP, Cruz lagunas B, Rojas Hernández S, Olivares Pérez J, Ávila Morales B, Salem AH ZM, CAMACho DíAz LM. 2015. Elaboration and characterization of biological devil fish silage (Plecostomus spp.) with Lactobacillus spp. and molasses as an additive, in the lower basin of The Balsas River in The State of Guerrero, Mexico. Life Sci J. 12 (2s): 68-74.

Copes J, Pellicer K, Del Hoyo G, García N. 2006. Producción de ensilado de pescado en baja escala para uso de emprendimientos artesanales. Analecta Vet. 26 (1): 5-8.

Crexi V, Souza Soares L, Pinto L. 2009. Carp (Cyprinus carpio) oils obtained by fishmeal and ensilage process: characteristics and lipid profiles. Int J Food Sci Tech. 44 (8): 16421648.

Cruz SuÁrez LE, Ricque Marie D, Nieto LóPez M, Tapia Salazar M. 2000. Revisión sobre calidad de harinas y aceites de pescado para la nutrición del camarón. En: CIVERA-CERECEDO
R, Pérez-Estrada CJ, Ricque-Marie D, Cruz-SuÁrez LE, editores. Avances en nutrición acuícola IV. Memorias del IV Simposium Internacional de Nutrición Acuícola. Noviembre 15-18, 1998. La Paz. 298-326 p.

DAPKeVICIUS MLE, RoBerT NOUT MJ, RombOUTS FM, Houben JH. 2007. Preservation of bluejack mackerel (Trachurus picturatus Bowdich) silage by chemical and fermentative acidification. J Food Process Preserv. 31: 454468.

De D, Sandeep KP, Sujeet Kumar, Ananda Raja R, MAHALAKSHMI P, SivaramaKrishNAN T, AMBASANKAR K, VIJAYAN KK. 2020. Effect of fish waste hydrolysate on growth, survival, health of Penaeus vannamei and plankton diversity in culture systems. Aquaculture. 524: 735240.

De Souza Batalha O. 2017. Silagem ácida de resíduos de pirarucu (Arapaima gigas, Schinz 1822) na alimentação de poedeiras comerciais leves [tesis de maestría]. Manaus: Instituto Nacional de Pesquisa da Amazônia-INPA. Pós-graduação em Agricultura no Trópico Úmido-PPGATU. 78 p.

Espinosa Chaurand LD, Vega Villasante F, Nolasco Soria H, Carrillo Farnés O, LÓPEZ LÓPEZ S. 2013. Perfil de aminoácidos del músculo de Macrobrachium tenellum y cómputo químico de proteínas usadas en su alimentación. Bol Inst Pesca São Paulo. 39 (4): 369-378.

[FAO] Food And Agriculture Organization. 1990. Curso regional sobre tecnología de productos pesqueros. Caracas: Programa de Cooperación Gubernamental. 3-15.

[FAO] Food and Agriculture Organization. 1995. Prácticas postcaptura y comercio. En: Código de conducta para la pesca responsable. Roma: FAO. 31-38. [consultado 7 julio 2020]. http://www.fao.org/3/a-v9878s.pdf.

[FAO] Food ANd Agriculture Organization. 2020. El estado mundial de la pesca y acuicultura. La sostenibilidad en acción. Roma: FAO. 
243 p. [consultado 7 julio 2020]. doi:10.4060/ ca9229es

Fernández Herrero A, Carrizo JC, Sánchez J. 2004. Ensilado químico del cornalito (Sorgentinia incisa). Inf Téc Int DNI-INIDEP $\mathrm{N}^{\circ}$ 7/2004. 2 p.

Fernández Herrero A, Fernández Compás A, MANCA E. 2015a. Ensayo preliminar de obtención de ensilado biológico de anchoíta (Engraulis anchoita), utilizando hez de malta de cebada (Hordeum vulgare L) como fuente de hidratos de carbono. Rev Electrón Vet. 16 (3).

Fernández Herrero A, Fernández Compás A, MANCA E. 2015b. Valor nutricional del ensilado láctico obtenido a partir de residuos del fileteado de Merluccius hubbsi. XVII Foro dos Recursos Mariños e da Acuicultura das Rías Galegas. 17: 245-251.

Fernández Herrero A, Fernández Compás A, SAlomone A, VitTone M. 2017b. Utilización de inoculo comercial para la producción de ensilado de pescado. Estudio preliminar. Rev Electrón Vet. 18 (9).

Fernández Herrero A, Fernández Compás A, Salomone A, Vittone M, Manca E. 2016. Fermentación láctica del residuo de Merluccius hubbsi. Evaluación de la calidad nutricional. Rev Electrón Vet. 17 (7).

Fernández Herrero A, Incorvaia I, Manca E. 2009. Obtención de ensilado químico a partir de residuos de bacalao criollo (Salilota australis). Inf Invest INIDEP N 21/2009. 6 p.

Fernández Herrero A, López A, Gorriti Goroso B, Vittone M, Chame D, Mendiolar M. 2019c. Utilización de un ensilado biológico de merluza como medio de cultivo para la microalga marina Nannochloropsis oculata. Inf Invest INIDEP No 53/2019. 17 p.

Fernández Herrero A, Macchiavello DG, SAlomone A. 2019a. Elaboración de ensilado biológico de residuos de mero (Acanthisthius patachonicus. Jenyns, 1840) utilizando inóculo agrícola. XXII Foro Rec Mar Ac Rías Gal. 21: 363-371.
Fernández Herrero A, Tabera A, Agüeria D, MANCA E. 2013. Obtención, caracterización microbiológica y físico-química de ensilado biológico de anchoíta (Engraulis anchoita). Rev Electrón Vet. 14 (2).

Fernández Herrero A, Tabera A, Agüería D, Sanzano P, Grosman F, Manca E. 2011. Obtención, caracterización microbiológica y físico-química de ensilado biológico de carpa (Cyprinus carpio). Rev Electrón Vet. 12 (8). Fernández Herrero A, Vittone M. $2019 \mathrm{~b}$. Ensilado químico de merluza (Merluccius hubbsi) con ácido fórmico como insumo proteico en la cría de lenguado. Inf Ases Transf INIDEP No 46/2019. 5 p.

Fernández Herrero A, Vittone M, Fernández Compás A. 2015c. Aspectos nutricionales del ensilado de residuos de corvina rubia (Micropogonias furnieri) obtenido por fermentación láctica. Inf Invest INIDEP No 106/2015. 11 p. Fernández Herrero A, Vittone M, Fernández Compás A. 2018. Aspectos nutricionales de ensilados químicos de merluza (Merluccius hubbsi). Inf Invest INIDEP No 80/2018. 11 p.

Fernández Herrero A, Vittone M, Massa A, MANCA, E. 2008. Obtención, caracterización microbiológica y físico-química de ensilados químicos de merluza (Merluccius hubbsi). En CD de resúmenes. III Simposio de Acuicultura ACUACUBA 2008. II Taller Regional de Producción y Utilización de Ensilados de Pescado para la Alimentación Animal y Taller de Acuicultura Marina. 15 al 18 de Septiembre de 2008. La Habana.

Fernández Herrero A, Vittone M, SAlomone A. 2017c. Obtención y caracterización de ensilado biológico de residuos de Merluccius hubbsi. Inf Ases Transf INIDEP No 88/2017. 7 p.

Fernández Herrero A, Vittone M, Salomone A. 2017d. Caracterización de la fracción proteica de ensilados biológicos de residuos de Micropogonias furnieri. XIX Foro Rec Mar Ac Rías Gal. 19: 251-269. 
Fernández Herrero A, Vittone M, Salomone A, Fernández Compás A. 2017e. Obtención y caracterización de ensilado químico de residuos de Merluccius hubbsi con ácido fórmico. Inf Ases Transf INIDEP No 91/2017. 7 p.

Fernández Herrero A, Vittone M, Salomone A, Macchiavello D, Fernández Compás A. 2017a. Obtención y caracterización de ensilado químico de residuos de mero (Acanthistius patachonicus). Inf Invest INIDEP $\mathrm{N}^{\circ}$ 121/2017. 11 p.

Fernández Jeri A. 2002. Control de la Producción de Histamina durante el deterioro del pescado. [consultado 15 julio 2020].https://odont. info/control-de-la-produccion-de-histaminaen-el-deterioro-del-psca.html.

FerRaz de ARruda L. 2004. Aproveitamento do resíduo do beneficiamento da tilapia do nilo (Oreochromis niloticus) para obtencao de silagem e óleo como subproductos [tesis de maestría]. Sao Paulo: Escuela Superior de Agricultura Luiz de Quiroz, Universidad de Sao Paulo. 91 p.

GAMA ORTIZ AL. 2013. Utilización de subproductos de almeja y calamar para la elaboración de ensilados biológicos y su uso en dieta de camarón blanco (Litopenaeus vannamei) [tesis ingeniería]. La Paz: Departamento Académico de Ingeniería en Pesquerías, Universidad Autónoma de Baja California Sur. 50 p.

Gbogouri GA, Linder M, FAnni J, PARmentier M. 2004. Influence of hydrolysis degree on the functional properties of salmon by-products hydrolysates. J Food Sci. 69 (8): 615-622.

GónGORA HG. 2013. Optimización de los procesos de ensilado a partir de residuos de la industria pesquera y evaluación de nuevas aplicaciones en la alimentación animal [tesis doctoral]. Bariloche: Centro Regional Universitario Bariloche, Universidad Nacional del Comahue. $131 \mathrm{p}$.

Góngora HG, Ledesma P, Lo Valvo VR, Ruiz AE, BRECCIA JD. 2012. Screening of lactic acid bacteria for fermentation of minced was- tes of Argentinean hake (Merluccius hubbsi). Food Bioprod Process. 9: 767-772.

GóngORA HG, RuIZ AE. 2008. Experiencia piloto de alimentación porcina con ensilado químico de pescado en el valle inferior del Río Chubut. Naturalia Patagónica. 4 (1): 118-126.

GONZÁlez D, MARÍN M. 2005. Obtención de ensilados biológicos a partir de los desechos del procesamiento de sardinas. Revista Científica FCV-LUZ. 15 (6): 560-567.

GuEDES RDO. 2012. Produção de silagem biológica a partir de coprodutos do processamento de pescado e fontes de carbono de baixo custo [tesis de maestría]. Dourados: Faculdade de Engenharia, Universidade Federal da Grande Dourados. $81 \mathrm{p}$.

Harrabi H, Leroi F, Mihoubi B. 2017. Biological silages from Tunisian shrimp and octopus byproducts. J Aquatic Food Prod Technol. 26 (3): 279-295.

Holguín MS, Caicedo LA, Veloza LC. 2009. Estabilidad de almacenamiento de ensilados biológicos a partir de residuos de pescado inoculados con bacterias ácido-lácticas. Rev Med Vet Zoot. 56: 95-104.

Huss HH, editor. 1998. El pescado fresco: su calidad y cambios de su calidad. FAO Documento Técnico de Pesca. 348. 202 p. [consultado 15 julio 2020]. http://www.fao.org/3/v7180s/ v7180s00.htm.

[ICA] Instituto Colombiano Agropecuario. 1999. Alimentos para animales: parámetros microbiológicos. Bogotá. 1-3 p.

[ICMSF] INTERNATIONAL COMMISSION ON MiCROBiOlogical Specification for Foods. 1983. Microorganismos de los alimentos. 1. Técnicas de análisis microbiológicos. Zaragoza: Editorial Acribia S.A.

JATOBÁ RF, OliveIRA Filho PR. C. 2017. Silagem biológica elaborada com residuos de filetagem de saramunete (Pseudupeneus maculatus). Rev Bras Eng Pesca. 10 (1): 58-68

Khodanazary A, Hajimoradloo A, Ghorbani R. 2013. Influence of solid-state fermentation 
on nutritive values and enzymatic activities of Anchovy Kilka (Clupeonella engrauliformis Svetovidov, 1941) meal by using different microorganisms. Intl Res J Appl Basic Sci. 4 (8): 2357-2367.

KRISTINSSON HG, RAsCO BA. 2000. Biochemical and functional properties of Atlantic salmon (Salmo salar) muscle proteins hydrolyzed with various alkaline proteases. J Agric Food Chem. 48: 657-666.

Lee YB, Elliot JG, Rickansrud DA, Mugberg EC. 1978. Predicting protein efficiency ratio by the chemical determination of connective tissue content in meat. J Food Sci. 43: 1359-62.

LIRA SÁNCHEZ JR. 2010. Suplementación con ensilado de pescado en vacas lactantes [tesis de Médico Veterinario Zootecnista]. Veracruz: Facultad de Medicina Veterinaria y Zootecnia, Universidad Veracruzana. $67 \mathrm{p}$.

Llanes Iglesias J, Toledo PéRez J, Fernández VAldez I, LAZO dE LA Vega J. 2007a. Estudio del ensilado biológico del pescado como inóculo de bacterias ácido lácticas en la conservación de desechos pesqueros. Rev Electrón Vet. 8 (9).

Llanes Iglesias J, Toledo Pérez J, Lazo de la Vega J. 2007b. Máximo porcentaje de ensilado químico de pescado en la dieta de Clarias gariepinus (Burchell, 1822). Rev Electrón Vet. 8 (9).

Llanes Iglesias J, Toledo Pérez J, Savón ValDÉS L, GutiÉrRez Borroto O. 2012. Utilización de silos pesqueros en la formulación de dietas semi-húmedas para tilapias rojas (Oreochromis niloticus x O. mossambicus). Revista Cubana de Ciencia Agrícola. 46 (1): 67-72. Lopes DE LIMA J, GOMES FA, BARRETO LV, RosA BL, DE Souza LP, Ferreira JB, De Freitas HJ. 2020. Silagem ácida e biológica de resíduos de peixes produzidos na Amazônia ocidental - Acre. Braz J Develop. 6 (6): $36677-$ 36693.

Maia Junior WM, de Oliveira Sales R. 2013. Propiedades Funcionais da obtencao da sila- gem ácida e biológica de residuos de pescado. Uma revisao. Rev Bras Hig Sanid Anim. 7 (2): 126-156.

MAnCA E, CARrizo JC. 2002. Informe final de producción y utilización de ensilados en la formulación de dietas. Proy. DNA/INIDEP. Expte. 4961.

Muhammed MA, Domendra D, Muthukumar SP, SAKHARE PZ, BHASKAR N. 2015. Effects of fermentatively recovered fish waste lipids on the growth and composition of broiler meat. Br Poul Sci. 56 (1): 79-87.

[NRC] National Research Council. 1993. Nutrient requirements of fish. Washington: National Academy Press. 115 p.

Olsen RL, Toppe J. 2017. Fish silage hydrolysates: No only a feed nutrient, but also a useful feed additive. Trends Food Sci Technol. 66: 93-97.

Olsen RL, Toppe J, Karunasagar I. 2014. Challenges and realistic opportunities in the use of by-products from processing of fish and shellfish. Trends Food Sci Technol. 36: 144-151.

Ortega Toro R, Hoyos CONCHA JL. 2016. Residuos piscícolas a ensilaje biológico: evaluación fisicoquímica. Publ Investig. 10: 13-20.

Osorio Contreras MA. 2014. Producción de harinas obtenidas a partir de coproductos de la industria del fileteado del pescado en Colombia [tesis de maestría]. Bogotá: Facultad de Medicina Veterinaria y de Zootecnia, Universidad Nacional de Colombia. 123 p.

Ovissipour M, ABEDiAn AM, MotamedZADEGAN A, Rasco B, Safari R, Shahiri H. 2009. The effect of enzymatic hydrolysis time and temperature on the properties of protein hydrolysates from the Persian sturgeon (Acipenser persicus) viscera. Food Chem. 115: 238-242.

Ovissipour M, Abedian Kenari A, MotamedZADEGAN A, NAZARI R. 2010. Optimization of enzymatic hydrolysis of visceral waste proteins of yellowfin tuna (Thunnus albacares). Food Bioprocess Technol. 5: 696-705. 
doi:10.1007/s11947-010-0357-x

Özyurt G, GöKdoĞAn S, ŞIMŞEK A, Yuvka I, Ergüven M, Kuley Boga E. 2015. Fatty acid composition and biogenic amines in acidified and fermented fish silage: a comparison study. Arch Anim Nutr. 70: 72-86. doi:10.1080/ 1745039X.2015.1117696

Özyurt G, ÖzKÜTÜK A, BoĞA M, Durmuş M, BoĞA EK. 2017. Biotransformation of seafood processing wastes fermented with natural lactic acid bacteria; the quality of fermented products and their use in animal feeding. Turkish J Fish Aquat Sci. 17: 543-555.

Palkar ND, Koli JM, Patange SB, ShaRangdhar ST, Sadavarte RK, Sonavane AE. 2017. Comparative study of fish silage prepared from fish market waste by using different techniques. Int Curr Microbiol App Sci. 6 (12): 3844-3858.

Panné Huidobro S. 2019. Producción acuícola destinada al consumo humano en Argentina durante el año 2019. Coordinación de acuicultura y promoción del consumo interno. Subsecretaría de Pesca y Acuicultura. Ministerio de Agricultura, Ganadería y Pesca. [consultado 9 noviembre 2020]. https://www.magyp.gob.ar/ sitio/areas/acuicultura/estadisticas/ archivos/ 000000 Producci\%C3\%B3n/190000 Producci\%C3\%B3n\%20de\%20Acuicultura $\%$ 20destinada $\% 20$ al $\% 20$ consumo $\% 20$ en $\% 20$ Argentina\%20-\%202019.pdf.

Panné Huidobro S, Álvarez A, Fernández Herrero A, Manca e, Martin S, Rossi R, WiCKI G. 2006. Puesta a punto de las metodologías para desarrollo de ensilados biológicos. En: Desarrollo y estandarización de tecnologías para la producción de alimentos para peces y de productos pesqueros con añadido de valor”. CFI - Dirección de Acuicultura: 67-99.

Parisuaña Callata J, Churacutipa Mamani M, Salas A, Barriga Sánchez M, Araníbar MJ. 2018. Ensilado de residuos de trucha en la alimentación de ovinos de engorde. Rev Inv Vet Perú. 29 (1): 151-160.
Perea Román C. 2016. Evaluación nutricional de ensilajes de residuos de trucha arcoíris Oncorhynchus mykiss en la alimentación de tilapia roja Oreochromis spp. [tesis doctoral]. Palmira: Facultad de Ciencias Agropecuarias, Universidad Nacional de Colombia. 190 p.

Perea Román C, Garcés Caicedo YJ, Hoyos Concha JL. 2011. Evaluación de ensilaje biológico de residuos de pescado en alimentación de tilapia roja (Oreochromis spp.). Biotecnol Sector Agropecuario Agroind. 9 (1): 60-68.

Perea Román C, hoyos Concha JL, Garcés Caicedo YJ, Muñoz Arboleda LS, Gómez PEÑARANDA JA. 2017. Evaluación de procesos para obtener ensilaje de residuos piscícolas para alimentación animal. Cienc en Desarro. 8 (2): 39-50.

PÖLÖNEN, I. 2000. Silage for fur animals. preservation efficiency of formic acid and benzoic acid in the ensiling of slaughterouse by-products and their subsequent metabolism in farmed fur animals [tesis doctoral]. Helsinki: Faculty of Agriculture and Forestry, University of Helsinki. 63 p.

Rai AK, SWAPNA CY, Bhaskar N, Halami PM, SACHINDRA NM. 2010. Effect of fermentation ensilaging on recovery of oil from fresh water fish viscera. Enzyme Microb Technoly. 46: 913.

RAMASUBburayan R, IYAPPARAJ P, SUBHASHINI KJ, Chandran MN, Palavesam A, Immanuel G. 2013. Characterization and Nutritional quality of formic acid silage developed from marine fishery waste and their potential utilization as feed stuff for Common Carp Cyprinus carpio fingerlings. Turkish J Fish Aquat Sci. 13: 281-289.

RAMÍREZ A. 2013. FAO consultant. Innovative uses of fisheries by-products. Globefish Research Programme. Vol. 110. Roma: FAO. 53 p.

RAMÍREZ RAMírEZ JC. 2009. Aprovechamiento de fauna de acompañamiento del camarón y subproductos pesqueros mediante la elaboración de ensilado de pescado [tesis doctoral]. Iztapa- 
lapa: Universidad Autónoma Metropolitana, Unidad Iztapalapa. 158 p.

Ramírez Ramírez JC, GutiÉrRez R, UlLOA JA, Rosas P, Torres G, Bautista PU. 2018. Utilization of fish and mango wastes on biological silage production. Curr Res Agric Sci. 5 (1): 6-14.

RAMíreZ RAMírez JC, IBARRA JI, ROMERO FA, Ulloa PR, Ulloa JA Matsumoto KS, Vallejo Córdoba B, Mazorra Manzano MA. 2013. Preparation of biological fish silage and its effect on the performance and meat quality characteristics of quails (Coturnix coturnix japonica). Braz Arch Biol Technol. 56 (6): 1002-1010.

Reyes Ramos M. 2010. Manual para la elaboración de ensilado ácidos de pez diablo (Hypostomus plecostomus). Instituto Tecnológico de la Región Sierra. Teapa. Tabasco. 16 p.

RODRíGueZ PH, ROJAS MS. 2014. Efecto de dietas enriquecidas con vitamina e y selenio orgánico en el comportamiento productivo y calidad funcional del filete de trucha arco iris (Oncorhynchus mykiss). Rev Inv Vet Perú. 25 (2): 213-225.

Roтн FX. 2000. Ácidos orgánicos en nutrición porcina: eficacia y modo de acción. En: Avances en nutrición y alimentación animal: XVI Curso de especialización FEDNA / Coord. por Rebollar, Carlos de Blas Beortegui, Gonzalo G. Mateos. 9: 169-181.

Sánchez E, Benites E, Ubillus E, Ochoa G. 2013. Efecto de tres niveles de ensilado biológico de cabeza de Penaeus vannamei, en alimentación de cerdos (Sus escrofa) en las etapas fisiológicas de gestación y lactación. Revista Manglar. 10 (2): 27-38.

Sánchez Torres H, Juscamaita Morales J, Vargas Cárdenas J, Oliveros Ramos R. 2008. Producción de la microalga Nannochloropsis oculata (Droop) Hibberd en medios enriquecidos con ensilado biológico de pescado. Ecol Apl. 7 (1-2): 149-158

Sánchez Trujillo SM, Hurtado Pinzón AJ,
Toro Silva J, Hoyos Concha JL. 2016. Evaluación a nivel piloto del proceso de ensilaje biológico de residuos de Oncorhynchus mykiss. Agron Colombiana. 34 (1 Supl.): S1303-S1307.

SCHUCHARDT D. 2005. Requerimientos nutricionales en bocinegro (Pagrus pagrus) [tesis doctoral]. Las Palmas de Gran Canaria: Universidad de Las Palmas de Gran Canaria. 244 p.

Seibel NF, Souza SoAres LA. 2003. Production of chemical silage from marine residue. Brac $\mathrm{J}$ Food Technol. 6 (2): 333-337.

SEsto A. 2010. Ensilado biológico de carpa común (Cyprinus carpio). Obtención, caracterización físico-química y microbiológica [tesis de licenciatura]. Tandil: Facultad de Ciencias Veterinarias, Universidad Nacional del Centro de la Provincia de Buenos Aires. 54 p.

SGARBIERI VC. 1987. Alimentacao e nutricao: fator de saude e desenvolvimento. Campinas: Editora da UNICAMP. São Paulo: Almed. 387 p.

ŠližYte R, DAukšAs E, FAlch E, Storrø I, RusTAD T. 2005. Characteristics of protein fractions generated from cod (Gadus morhua) byproducts. Process Biochem. 40: 2021-2033.

Sousa E, da Silva J, Cavalcanti F, Bussons I, MACHADO M. 2016. Use of biological silage in diets for fish of Brycon amazonicus (Spix \& Agassiz, 1829) fingerlings. Int J Fish Aquat Stud. 4 (6): 518-521.

Sosa EsPinOZa CF. 2017. Elaboración de ensilado biológico a partir de residuos de paiche (Arapaima gigas) [tesis de Ingeniero Pesquero]. Lima: Facultad de Pesquería, Universidad Nacional Agraria La Molina. 89 p.

Spanopoulos Hernández M, Ponce Palafox JT, Barba Quintero G, Ruelas InZunZa JR, TizNADO CONTRERAS MR, HERNÁNDEZ GONZÁLEZ C, Shirai K. 2010. Producción de Ensilados Biológicos a partir de desechos de pescado, del ahumado de atún de aleta amarilla (Thunnus albacares) y del fileteado de Tilapia (Ore- 
ochromis sp.), para la alimentación de especies acuícolas. Rev Mex Ing Quim. 9 (2): 167178.

TAnuja S, Kumar A, Nayak SK. 2017. Effect of dietary intake of acid ensiled fish waste on the growth, feed utilization, hematology and serum biochemistry of rohu Labeo rohita, (Hamilton, 1822) fingerlings. Indian J Anim Res. 51 (3): 501-505.

Terrones España S, Reyes Avalos W. 2018. Efecto de dietas con ensilado biológico de residuos de molusco en el crecimiento del camarón Cryphiops caementarius y tilapia Oreochromis niloticus en co-cultivo intensivo. Sci Agropecu. 9 (2): 167-176.

Tezel R, GÜllü K, Alişarli M, Ekici K, GüZel Ş. 2016. A study on chemical and microbiological composition of silage made of industrial fisheries processing waste. Mugla J Sci Technol. 2 (1): 30-37.

Toledo Pérez J, Llanes Iglesias J. 2006. Estudio comparativo de los residuos de pescado ensilado por vías bioquímica y biológica. Revista AquaTIC. 25: 28-33.

Ulfah Karim N, Mohd Ali Lee MF, Mat ARshaD A. 2015. The effectiveness of fish silage as organic fertilizer on post- harvest quality of pak choy (Brassica rapa L. subsp. chinensis). Eur Int J Sci Technol. 4 (5): 163174.

Valenzuela C, Carvallo F, Moralesa MS, REYes P. 2015. Efecto del uso de ensilado seco de salmón en dietas de pollos broiler sobre parámetros productivos y calidad sensorial de la carne. Arch Med Vet. 47: 53-59.

VÁzQuez JA, Rodrigues AC, Fuciños P, PAsTRANA L, MuRADO MA. 2010. Bio-silage of mussel work-processing wastes by lactobacilli on semi-solid culture. J Food Eng. 97: 355359.

VÁSQUEZ Zuluaga SA. 2015. Estudio del proce- so de ensilaje de vísceras de cachama blanca (Piaractus brachypomus) utilizando el método químico y el biológico con melaza y suero lácteo como sustrato [tesis de maestría]. Medelín: Universidad de Antioquia. 101 p. Vidotti RM, Bertoldo MT, Gonçalves GS. 2011. Characterization of the oils present in acid and fermented silage produced from Tilapia filleting residue. Rev Bras Zootecn. 40 (2): 240-244.

Vidotti RM, Macedo Viegas EM, CAREIRo DJ. 2003. Amino acid composition of processed fish silage using different raw materials. Anim Feed Sci Tech. 105: 199-204.

VigLEZZI V. 2012. Elaboración de ensilado químico a partir de desechos de carpa común (Cyprinus carpio) utilizando ácidos fórmico y sulfúrico, con su posterior evaluación físicoquímica, microbiológica y sensorial [tesis de licenciatura]. Tandil: Facultad de Ciencias Veterinarias, Universidad Nacional del Centro de la Provincia de Buenos Aires. 51 p.

Wicki G, Galli Merino O, Caló P, Sal F. 2012. Use of High Content Fish Silage Wet Food in Final Growth out of Pacú (Piaractus mesopotamicus, Holmberg 1887) in Northeast Argentina. J Agric Sci Technol. B 2: 307-311. Yupanqui Pajuelo MG. 2013. Reciclaje de los residuos industriales del Jurel por medio de las Técnicas de hidrólisis [tesis ingeniería]. Truji1lo: Facultad de Ingeniería Química, Universidad Nacional de Trujillo. 110 p.

ZÁrATE R. 2013. Argentina Innovadora 2020. Plan Nacional de Ciencia, Tecnología e Innovación. Mesa de Implementación del NSPE. Producción y Procesamiento de Recursos Oceánicos. Documento de Referencia. Secretaría de Planeamiento y Políticas en Ciencia, Tecnología e Innovación Productiva. Ministerio de Ciencia, Tecnología e Innovación Productiva. Argentina. 56 p. 